
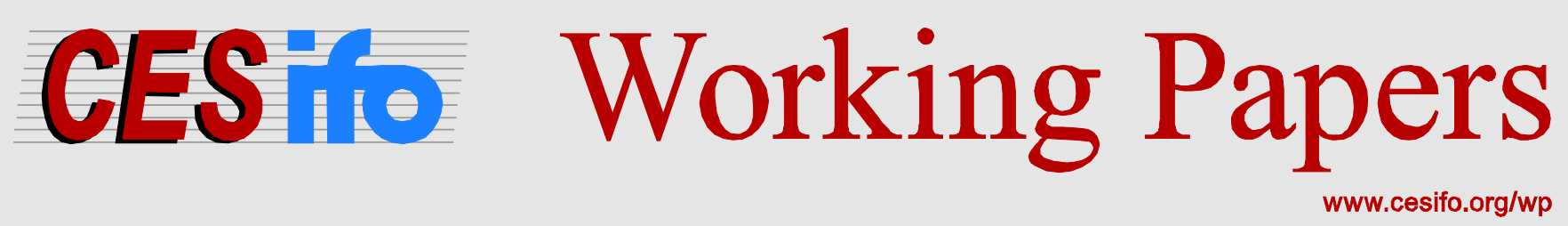

\title{
Firm Export Survival: Micro-Evidence from the Philippines
}

\author{
E.O. Annette Pelkmans-Balaoing \\ Gerrit Hugo van Heuvelen \\ Jean-Marie Viaene
}

CESIFO WORKING PAPER NO. 6270

CATEgory 8: TRAde Policy

DECEMBER 2016
An electronic version of the paper may be downloaded
- from the SSRN website:
- from the RePEc website:
- from the CESifo website:
WwW.SSRN.com
www.RePEc.org
www.CESifo-group.org/wp

\section{CESifo}




\title{
Firm Export Survival: Micro-Evidence from the Philippines
}

\begin{abstract}
This paper explores firms' export dynamics in emerging economies where local firms face stiff foreign competition, both at home and abroad, and thus compelled to choose the level of quality in which to export. We develop and test a model of vertical product differentiation where the link between export performance and product quality is central. The impact of other governmental decisions related to multiple uncertainties faced by exporters such as exchange rate, freight and trade policies, are investigated as well. A rich and new firm-level data base is employed, which matches the firm-coded trade transactions data (7-digit) of Philippine manufacturing firms, with their corresponding firm survey data from 1996-2007. Using discrete survival analysis, we show that export spells have a short duration, 20 months on average. Particularly $72.2 \%$ of trade relationships in year one do not survive to year two. Market uncertainties, particularly those linked to exchange rates and transport costs increase the probability of firm exit as expected. Export survival rates are highest among firms that select an export price contained in the interval between the median and mean of the international distribution of product prices. In contrast, those choosing a price located at both ends of this distribution have the least chance of survival.
\end{abstract}

JEL-Codes: F100, F140.

Keywords: intra-product trade, product quality, firm dynamics, survival analysis, multiple uncertainty.

\section{E.O. Annette Pelkmans-Balaoing Erasmus University School of Economics Rotterdam / The Netherlands pelkmans@ese.eur.nl}

\author{
Gerrit Hugo van Heuvelen \\ Erasmus University \\ Tinbergen Institute \\ Rotterdam / The Netherlands \\ harrovanheuvelen@gmail.com
}

\author{
Jean-Marie Viaene \\ Erasmus University \\ Faculty of Economics \\ Rotterdam / The Netherlands \\ viaene@ese.eur.nl
}

December 15, 2016

This paper is part of the WOTRO-NWO intregrated programme titled "Escaping the Middle-Income Trap" whose financial support is gratefully acknowledged. We are also grateful to seminar participants at CESifo (Munich), Erasmus University and the University of the Philippines for helpful comments and suggestions. Part of this paper was written while J.-M. Viaene was visiting the Center for Economic Studies (CES) of the University of Munich whose hospitality and financial support were generously provided. We further thank Anita Breva, Florence, Dulce A. Regala, Estela T. De Guzman, Ralph P. Bariata and Jeng P. Soliven for help with the data collection. We are also grateful to the Philippine Statistical Authority (PSA) for access to confidential data. In this regard, PSA had the right to review the paper prior to dissemination. The views expressed in the paper are these of the authors and do not necessarily represent those of the PSA. 


\section{Introduction}

Export or perish is a public utterance commonly repeated by influential leaders in active support of a country's exports. For firms, it is important to look for more foreign markets as trade allows them to spread R\&D expenditure across markets. For policymakers of developing countries, a presence in foreign markets contributes to macroeconomic stability when negative shocks hit the domestic economy. Besides, trade contributes to increased production efficiency through reallocations across firms and/or sectors. However, firm data reveal a different picture in that low survival rates are observed in terms of both exported products and destinations. Given this, the following questions are often raised: (i) Which are the factors that explain a firm's export dynamics in the global economy? (ii) Particularly what factors keep a firm exporting once it starts to export? (iii) What determinants explain export spells, exit and re-entrance of exporters? The objective of this paper is to address these issues empirically and see how governments of developing countries can design policies to promote firms' export success.

To that end, we use a rich and new firm-level database for the Philippines which has been collected by the Philippine Statistical Authority (PSA) over the years 1996-2007. The data set matches the firmcoded trade transactions data (7 digits) of Philippine manufacturing firms with their corresponding firm survey data that are available for that period. In total, the sample includes 5,472 firm names, 5,048 different products and 250 destinations to which firms export. Using discrete survival analysis, we empirically analyse firms' exporting spells and explore the determinants of Philippine exporting firms' survival abroad, including proxies for product quality. The case of the Philippines is important since the country is classified as a lower-middle income economy in World Bank's 2015 country groups while other countries in the region like South Korea but also China, Malaysia and Thailand moved to a higher country grouping years ago. As the Philippines have been in this position for 5 decades, the questions of this paper assume considerable importance.

Discrete survival analysis links the duration of export spells to a number of explanatory variables. The estimation techniques have been developed and used in many areas, particularly health and labor economics (e.g., Kelly and Lim, 2000; van den Berg, 2001; Skrondal and Rabe-Hesketh, 2012). In the trade literature, a first application of these techniques is contained in Besedes and Prusa (2006) who find that the duration of bilateral trade relationships is generally short-lived due to various reasons, in particular destination market characteristics. Other applications are found in Görg et al. (2007), Nitsch (2009), Fugazza and Molina (2009) and Brenton et al. (2009). Most trade literature has used Cox models and discrete-time equivalent Cox models, namely the complementary log-log model to analyze these export spells. In reaction to Besedes and Prusa (2006), Hess and Persson (2012) formulate a number of objections regarding the application of this method to trade data. For example, given that most samples consists of yearly observations, there is interval censoring which requires a discrete survival approach. Finally, the estimation technique should include random effects

to correct for unobserved heterogeneity of exporting firms. Our estimation techniques encompass these methodological changes.

In our search for a theoretical foundation for our empirical analysis, we found models of vertical product differentiation to be well suited to take up the task of explaining firms' export survival. These models stress the importance of differences in income per capita across countries and of differences in the number of potential consumers. Product quality is a strategic variable and firms' incentives to 
enter and exit bilateral trade relationships are part of stable Nash equilibria. The heterogeneous-firms trade theory was another prime candidate in our search as it draws a distinction between exporting and non-exporting firms by theorizing that only the most productive ones export (Eaton and Kortum, 2002; Melitz, 2003). However, though productivity draws may explain firms export behavior in the long- run they seem insufficient to explain the firm's export dynamics in the transition periods. This view is shared by Bernard et al. (2009) who look at the sources of US export growth and conclude that findings are at odd with the conventional view that export growth is the result of domestic firms becoming more productive. That is true only in the long-run. In the short-run, almost all growth comes from higher demand for products that existing firms already made.

If product quality is indeed important for export performance then we should find that high-quality exporting firms perform better than non-upgrading exporting counterparts. Probably the single best indicator of export performance is the length of time that an exporter is able to sell his goods to foreign markets. If higher product quality leads to better export performance, then high-quality firms will remain exporters for longer time periods. This is indirectly another testable hypothesis that derives from the theoretical foundation.

In this vein, we analyze an international trade game between two firms located in two different countries (developed vs. developing) that produce quality-differentiated products. Several asymmetries characterize the model: (i) domestic and foreign consumers have heterogeneous preferences for quality and different income levels; (ii) markets are asymmetric in that both size and distribution of consumer tastes differ; and (iii) firms in developing countries face higher quality development costs to achieve any given quality level. Both firms operate under two constraints. Firstly, firms avoid dumping their products and the associated financial penalties by complying with the standard rules of the WTO. Hence, the fob price of exports cannot be lower than the local price, both expressed in the same currency units. Secondly, as there is a time gap between the production date and the payment date for goods, exporting firms face multiple uncertainties and exhibit a forward-looking behavior regarding their entry-exit decisions in foreign markets. Prime sources of uncertainty include government policies, transport costs and fluctuations in exchange rates. Given these, firms play a two-stage game. In the first stage, firms select qualities to be produced and possibly exported, and incur the fixed costs; in the second stage, firms engage in a price competition game. Once the market equilibrium is obtained uncertainty is resolved.

There is increasing empirical evidence supporting the main features of our analysis. Of the 2966 anti-dumping measures reported by the WTO between January 1995 and June 2014, remarkably few concerned the Philippines: only 11 were imposed by Philippine authorities and 7 against Philippine export firms. Also, Rauch's (1999) classification of goods (revised July 2007) codes internationally traded commodities according to three possible types: differentiated, reference priced, or homogeneous good. Based on this classification, $85 \%$ of Philippine manufacturing firms produced products that are differentiated. ${ }^{1}$

Another important factor affecting firms' foreign trade is the volatility of major currencies of the world. For example in Figure 1, the Philippine Peso / US\$ rate and its volatility (approximated by the coefficient of variation) are displayed for the period January 1990 to December 2014. The figure

\footnotetext{
${ }^{1}$ Using Rauch's (1999) liberal classification
} 
Figure 1: The Philippine Peso/US\$ exchange rate

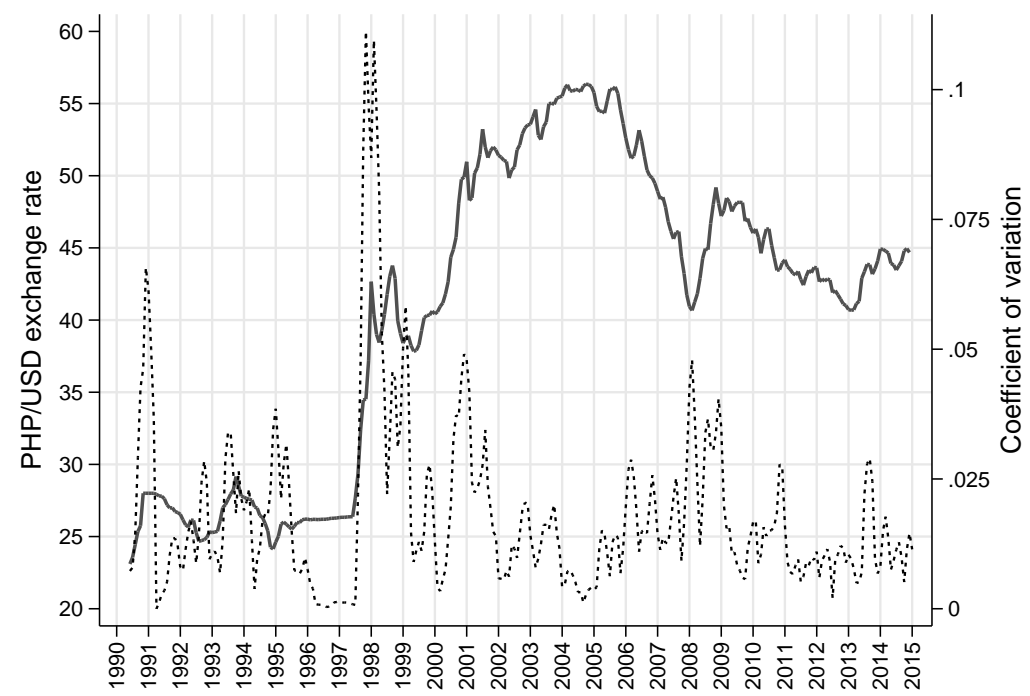

Notes: (i) The bold line displays the monthly Philippine Peso / US\$ exchange rate over the period January 1990 to December 2014 (monthly averages); (ii) The broken line shows the rolling coefficient of variation with a rolling window of 5 months.

Source: Own calculations based on exchange rate data from Bangko Sentral NG Philipinas.

Figure 2: Median transport costs for semi-conductors to Singapore

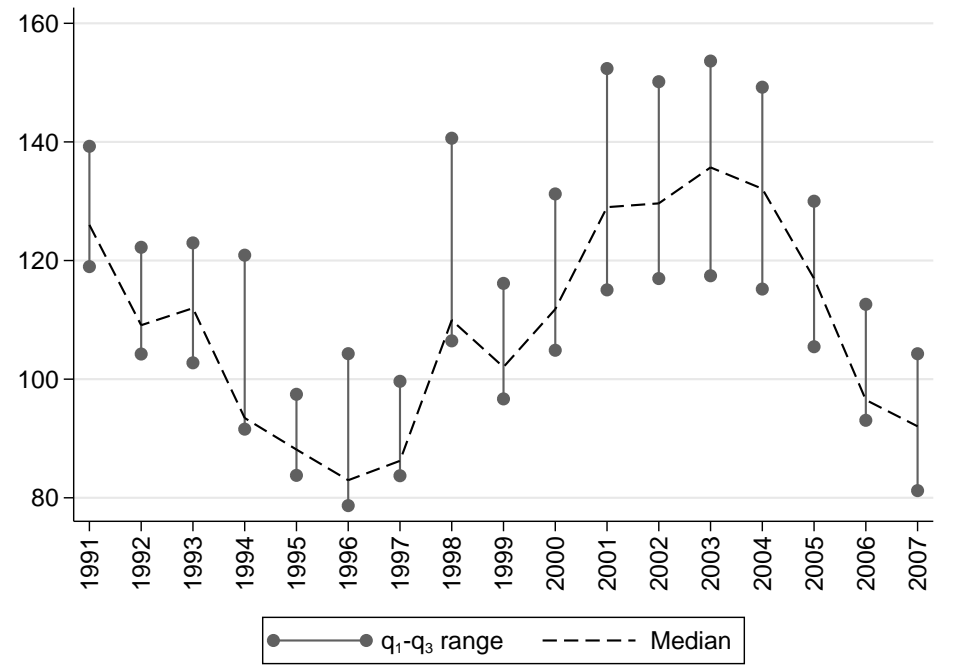

Notes: (i) This graph reproduces firms real transport cost in pesos of exporting semi-conductors to Singapore over the period 1991 to 2007; (ii) Units are expressed in pesos per kg, deflated by the Filipino CPI (2005=100); (iii) The product code is Pscc 9310221, formally called Semi-conductors manufactured using materials by consignment basis; (iv) The dotted line displays the median transport cost across exporting firms; the vertical bar shows the 25 th- 75 th percentile

Source: Own calculations based on data from the PSA.

shows large swings in the level of the currency where a period of depreciations ( $151 \%$ up to October 2004 ) is followed by a period of appreciations (20.7\% till December 2014). The volatility fluctuates as well, particularly during the Asian crisis of 1997-1998 and the financial crisis of 2008-2009. Likewise, freight costs that are important for island economies are also volatile. This is shown in Figure 2 which displays the real freight costs of exporting a single 7 digit product, semi-conductors, to a single 
destination, namely Singapore. Besides the time variation in the median transport costs, there is a substantial dispersion of these costs across Philippine exporters. Finally, Handley (2014) shows that trade policies can be a contributor to background uncertainties firms face when making their export decisions. Altogether these fluctuations subject firms to both "level" and "risk" effects.

Given this framework, we derive the following main results: (i) We show the existence of a unique (risk-dominant) free trade equilibrium where the foreign firm, being more efficient, produces a good of higher quality than the domestic firm. Though conditional on prices different quality levels are observed, relative prices are $\log$-linear in relative qualities. The latter results extend to models with higher dimensions. (ii) Under some parameter configurations, the domestic firm exits strategically the export market. (iii) The estimated discrete-time hazard function reveals that export spells have a short duration, the mean being 20 months. Particularly in year one, $72.2 \%$ of trade relationships do not survive to year two. (iv) The Philippine exporting firms with a higher survival rate are those that price their exports between the median and mean of the international distribution of prices. In contrast, firms charging prices located at both ends of the distribution have the lowest survival rates. (v) Product quality matters as well. In order to sell in markets like South Korea, Thailand and the USA, Philippine firms decreased the relative quality of their products over time. (vi) Though uncertainty negatively affects the exporting firm survival, a real depreciation of the Philippine pesos explains longer export duration, together with learning by exporting and network effects.

The rest of the paper is organized as follows. The next section reviews and interprets the related literature. Section 3 presents the details of our theoretical model and discusses the results in light of the related literature. Section 4 describes the data, the econometric methods and the variable constructions. Section 5 provides empirical results and explores the quantitative implications of our results. Finally, Section 6 concludes. The online Appendix contains the proofs of our theoretical model, a detailed description of data sources and methods, and the variable definitions.

\section{Related Literature}

There is also substantial empirical evidence that product quality matters in the global economy. Bastos and Silva (2010) use micro-data from Portugal to uncover the quality of exports and their drivers. In a sample of 60 countries Hallack (2006) shows that there are large differences in the quality of products that are exported. Using a novel method to account for variation in trade balances induced by horizontal and vertical differentiation, Hallack and Scott (2011) substantiate the importance of product quality by tracing the evolution of manufacturing quality for the world's top exporters. Khandewal (2010) questions the standard assumption that a product quality is related to its unit value and proceeds to estimate quality for highly disaggregated US import data by focusing on properties of consumer demands. In contrast, Di Comite et al. (2014) stress the importance of separately accounting for product quality and production costs when using these unit values. Like in Khandelwal (2010), we show that conditional on prices, different quality levels are observed for different combinations of parameter values and realization of uncertain variables. Like in Di Comite et al. (2014), we obtain the result that quality is a relative concept, in that ratio of qualities is proportional to the ratio of prices.

Models of vertical product differentiation are particularly suited to understand firms' export dy- 
namics. The oligopoly problem starts with Shaked and Sutton (1984) who establish the well-known result that firms have generally an incentive to choose distinct quality levels in order to relax competition in a market. Other versions of this model include Krishna (1987) who compares trade policy instruments and Motta et al. (1997) who analyze the sustainability of quality leadership once countries open up to trade. More recently, Kugler and Verhoogen (2012) extend Melitz's (2003) framework to include the endogenous selection of input and output quality. Moraga-Gonzalez and Viaene (2015) is the contribution most closely related to our theoretical framework. They give a complete characterization of the export game between firms and derive conditions for reversals in quality leadership in developing economies. In our framework, we extend derivations of market equilibria by introducing multiple uncertainties in bilateral trade relationships together with a more thorough application of WTO rules.

More empirical evidence supports the main features of our analysis. For example, empirical estimates of Bastos and Silva (2010), Crozet et al. (2012) and Manova and Zhang (2012) provide support to characteristics of our market equilibria namely, that producers of high quality have higher outputs and charge higher prices. In addition, they find that firms adjust optimally the quality of their products to countries with a higher economic development. In addition, a key feature of sectors with a high degree of vertical product differentiation is the low price elasticity of demand, result empirically supported by Anderton (1999). Econometric studies by Crozet and Erkel-Rousse (2004) establish a tight link between quality and innovation, justifying a convex cost function of quality development that is typical of models of vertical product differentiation.

\section{The Theoretical Framework}

Two firms sell goods that are vertically differentiated. These two firms, located in two different countries, home and foreign, produce goods for their own market and, eventually, for exports. The firm located in the foreign (home) country is referred to as the foreign (home) firm and all foreign variables are denoted by an asterisk "*". We index destination countries by $i=1,2$ where subscript 1 refers to the home country and subscript 2 to the foreign country. We assume there are future transport costs unknown at the decision date, denoted by $\tilde{r}$, associated to the bilateral shipment of goods between countries. For convenience, we suppose transport costs are of the "iceberg" type. The unknown exchange rate, denoted by $\tilde{e}$, is defined as the units of domestic currency per unit of foreign currency. Also future ad valorem import tariffs are denoted $\tilde{\tau}$ and $\tilde{\tau}^{*}$ respectively.

Product quality may be one of two types: high-quality $q_{h}$ and low-quality $q_{l}$, with $q_{h}>q_{l}$. As in Shaked and Sutton (1984), Motta et al. (1997) and Moraga-Gonzalez and Viaene (2015) we adopt the cost specification of pure vertical product differentiation models, where the costs of quality mainly fall on fixed costs and involve only a small or no increase in unit variable costs. Particularly, once the home and foreign firm pick the quality of the good, they pay an own-currency fixed cost $C(q)=c q^{2} / 2, q=$ $\left\{q_{h}, q_{l}\right\}$ and $C^{*}(q)=c^{*} q^{2} / 2$ respectively; they produce at a marginal cost that is normalized to zero. ${ }^{2}$ The functions are increasing in $q$ so that high-quality is more expensive to produce.

\footnotetext{
${ }^{2}$ Adding small marginal costs of production makes computations cumbersome and obscures the presentation of the results substantially without adding further insights. The specification of the cost function could be more general without affecting results qualitatively.
} 
Assume there is a population of measure $m$ at home, of measure 1 abroad, with $0<m \leq 1$. Consumers will purchase at most one unit of the product from one of the two firms according to preferences given by the following quasi-linear (indirect) utility function: $V=\theta q-p$, if one unit of a good of quality $q$ is bought at price $\mathrm{p}$, and 0 otherwise. Parameter $\theta$ is consumer specific and measures the utility a consumer derives from consuming a unit of quality. Assume $\theta$ is uniformly distributed over $[0, \lambda \bar{\theta}]$ at home, and over $[0, \bar{\theta}]$ abroad, with $0<\lambda \leq 1, \bar{\theta}>0$. Let $p_{l}$ and $p_{h}$ be the prices for low- and high-quality products in the domestic country. Suppose, for a moment, that $p_{h}>p_{l}$, i.e., high quality is sold at a higher price, an assumption that will be verified later.

To aggregate individual demand into firms demand functions, the first step is to identify marginal consumers. A first consumer, denoted $\tilde{\theta}$, is indifferent between buying high quality or low quality. Using the utility function, one obtains $\tilde{\theta}=\left(p_{h}-p_{l}\right) /\left(q_{h}-q_{l}\right)$. Likewise, let $\hat{\theta}$ denote the consumer marginal to the market who is indifferent between acquiring the low-quality good or nothing at all, that is, $\hat{\theta}=p_{l} / q_{l}$. As the latter varies, market sizes are endogenous and, in equilibrium, both markets will not be fully served. Given this, the high-quality good is demanded by those consumers belonging to the interval $\tilde{\theta} \leq \theta \leq \lambda \bar{\theta}$ and the low-quality variant is demanded by those buyers such that $\hat{\theta} \leq \theta<\tilde{\theta}$. Therefore, with $\theta$ being uniformly distributed on $[0, \lambda \bar{\theta}]$ and, as previously assumed, measure $m$ being home population, demands for high- and low-quality products by the domestic market are:

$$
\begin{array}{ll}
D_{h}(.)=m \int_{\left(p_{h}-p_{l}\right) /\left(q_{h}-q_{l}\right)}^{\lambda \bar{\theta}} f(\theta) d \theta=\frac{m}{\lambda \bar{\theta}}\left(\lambda \bar{\theta}-\frac{p_{h}-p_{l}}{\left(q_{h}-q_{l}\right)}\right) \\
D_{l}(.)=m \int_{p_{l} / q_{l}}^{\left(p_{h}-p_{l}\right) /\left(q_{h}-q_{l}\right)} \\
f(\theta) d \theta=\frac{m}{\lambda \bar{\theta}}\left(\frac{p_{h}-p_{l}}{\left(q_{h}-q_{l}\right)}-\frac{p_{l}}{q_{l}}\right)
\end{array}
$$

where $f(\theta)$ is the density function. Proceeding in the same way we can compute the foreign demands for high- and low-quality goods:

$$
D_{l}^{*}(.)=\frac{1}{\bar{\theta}}\left(\frac{p_{h}^{*}-p_{l}^{*}}{\left(q_{h}-q_{l}\right)}-\frac{p_{l}^{*}}{q_{l}}\right), D_{h}^{*}(.)=\frac{1}{\bar{\theta}}\left(\bar{\theta}-\frac{p_{h}-p_{l}}{\left(q_{h}-q_{l}\right)}\right)
$$

where $p_{l}^{*}$ and $p_{h}^{*}$ are foreign prices of low- and high-quality, $p_{h}^{*}>p_{l}^{*}$. Note that one of the demands in (1) and (2) is met by imports. Using the pair of demands (1) and (2), the problem of the risk neutral domestic firm when it produces low quality is to find $p_{l}$ and $p_{l}^{*}$ so as to maximize the expected value of the following random profits:

$$
\tilde{\pi}=p_{l} D_{l}+\tilde{e}\left(1-\tilde{\tau}^{*}\right)(1-\tilde{r}) p_{l}^{*} D_{l}^{*}-\frac{c}{2} q_{l}^{2}
$$

Likewise the risk neutral foreign rival chooses $p_{h}$ and $p_{h}^{*}$ so as to maximize the expected value of its profits:

$$
\tilde{\pi}^{*}=\frac{(1-\tilde{\tau})(1-\tilde{r})}{\tilde{e}} p_{h} D_{h}+p_{h}^{*} D_{h}^{*}-\frac{c^{*}}{2} q_{h}^{2}
$$

Taking the first order conditions and solving for the Nash equilibrium yields the following prices in the domestic country:

$$
p_{l}=\frac{\lambda \bar{\theta}\left(q_{h}-q_{l}\right) q_{l}}{\left(4 q_{h}-q_{l}\right)}, p_{h}=\frac{2 \lambda \bar{\theta}\left(q_{h}-q_{l}\right) q_{h}}{\left(4 q_{h}-q_{l}\right)}
$$


In the foreign country we have $p_{l}^{*}=p_{l} / \lambda, p_{h}^{*}=p_{h} / \lambda$. Equilibrium prices thus depend upon all qualities and not directly upon random variables. Inserting the solution for prices in the respective profit functions lead to the following expected revenues and profits:

$$
\begin{aligned}
& E \tilde{\pi}=\frac{\bar{\theta} q_{h} q_{l}\left(q_{h}-q_{l}\right)}{\left(4 q_{h}-q_{l}\right)^{2}}\left(m \lambda+E \tilde{e}(1-\tilde{r})\left(1-\tilde{\tau}^{*}\right)\right)-\frac{c}{2} q_{l}^{2} \equiv E \tilde{R}_{l}-\frac{c}{2} q_{l}^{2} \\
& E \tilde{\pi}^{*}=\frac{4 \bar{\theta} q_{h}^{2}\left(q_{h}-q_{l}\right)}{\left(4 q_{h}-q_{l}\right)^{2}}\left(1+\lambda m E \frac{(1-\tilde{r})(1-\tilde{\tau})}{\tilde{e}}\right)-\frac{c^{*}}{2} q_{h}^{2} \equiv E \tilde{R}_{h}-\frac{c^{*}}{2} q_{h}^{2}
\end{aligned}
$$

where $E($.$) is the expectation operator, \tilde{R}_{l}$ and $\tilde{R}_{h}^{*}$ represent domestic and foreign revenues. ${ }^{3}$

\subsection{Risk-dominant Nash Equilibrium.}

Since there are two quality levels available for choice, $q_{l}$ and $q_{h}$, there is an export game where the domestic and foreign firms can freely pick which of the two qualities to offer and which prices to set in the two different countries. There are four relevant continuation games, each of them ensuing after the firms have picked a quality-and-export strategy profile. The quality-and-export strategy set of a firm i is $S_{i}=\left\{\left\{q_{l} \& X\right\},\left\{q_{h} \& X\right\}\right\}$ for $i=1,2$ where $\mathrm{X}$ stands for export to the other market. But we can exclude two of these strategies, namely when firms choose to produce similar quality levels. With Bertrand competition, it is clear that competition will drive prices down to zero and firm will make losses equivalent to quality developments costs.

This game has therefore two Nash equilibria. In one equilibrium, $\left\{q_{l} \& X, q_{h} \& X\right\}$, the domestic firm produces the low-quality product and in the alternative equilibrium, $\left\{q_{h} \& X, q_{l} \& X\right\}$, it is the home firm that produces high quality. As discussed in detail in Motta et al. (1997), Cabrales et al. (2000), and Moraga-Gonzalez and Viaene (2015), the selection of equilibria in this type of games requires to use the Harsany-Selten risk-dominance criterion. Applying this criterion to our game, the next proposition characterizes the assignment of qualities across firms under free trade.

Proposition 1 In the unique risk-dominant free trade equilibrium, the foreign firm produces high quality and the domestic firm chooses low quality as long as $c>c^{*} E \tilde{e}$.

The proof of this proposition is contained in the Appendix to facilitate the reading. From Proposition 1 it is clear that quality leadership is obtained by computing cost differences whence these costs are expressed in similar currency units. The quality leader is thus the most efficient firm in terms of development costs. This important result indicates that the sustainability of quality leadership under

\footnotetext{
${ }^{3}$ It is possible to be more specific about the quality cost $C(q)=c q^{2} / 2, q=\left\{q_{h}, q_{l}\right\}$ by specifying, like in Verhoogen (2008) and Kugler and Verhoogen (2012), a Cobb-Douglas production function for quality that includes foreign inputs. Consider a production function that combines skilled labor $\mathrm{S}$ and foreign inputs $I^{*}: q=S^{\alpha} I^{* \beta}$. The corresponding long-run cost function for quality is indeed $c q^{2} / 2$ with $\alpha=\beta=.25$ and $c=4 \sqrt{w r}$ where $\mathrm{w}$ is skilled labor wage and $\mathrm{r}$ the domestic price of foreign inputs (thus including the exchange rate and any import tariff). Being $q=S^{.25} I^{* .25}$, the underlying production function implies large decreasing returns to scale in quality production. Since skilled labor is generally in short supply in developing economies, home exporters seeking quality upgrading are likely to be large importers of foreign inputs as well. This is one of the channels: (i) through which trade liberalization matters (see e.g. Goldberg et al., 2009; Khandelwal et al., 2013; Bas and Strauss-Kahn, 2015); (ii) that affect the pass-through of exchange rates (Amity et al., 2014) and; (iii) that lead to the equivalence between exchange rate depreciations and increased import tariffs (Feenstra, 1989).
} 
free trade hinges on firms' cost asymmetries, thus also on the expected exchange rate but neither on market size $\mathrm{m}$ nor on income difference $\lambda$.

\subsection{Trade Equilibrium}

The free maximization of profits (3) and (4) with respect to prices may not obey WTO rules on dumping. For example dumping by the foreign firm into the domestic market does not occur if the expected international foreign currency price of high-quality exports is not less than the local price:

$$
p_{h} U^{*} \geq p_{h}^{*}
$$

where $U^{*}=E[(1-\tilde{\tau})(1-\tilde{r}) / \tilde{e}]$ is the expectation of multiple uncertainties faced by the foreign firm. Vice versa, dumping by the local firm abroad takes place if the international foreign currency price of low-quality exports is not less than the home price:

$$
p_{l}^{*} U \geq p_{l}
$$

where $U=E\left[\tilde{e}(1-\tilde{r})\left(1-\tilde{\tau}^{*}\right)\right]$ is the expectation term of the home firm. Both $U$ and $U^{*}$ represent the expectation of destination-specific bilateral export uncertainties, the latter for the home firm that exports to the richer country, the former for the foreign firm. They are equal to unity in a world of fixed exchange rates (specifically, $e=1)$, no transport cost $(r=0)$ and no tariff $\left(\tau=\tau^{*}=0\right)$. Let us define $\mu=q_{h} / q_{l}$ with $\mu>1$ since $q_{h}>q_{l}$. It is now possible to characterize the trade equilibrium resulting from the allocation of qualities given by Proposition 1 and after imposing constraints (7) and (8). The different steps of the derivations of the trade equilibrium are contained in the Appendix.

With endogenous qualities, the constrained trade equilibrium involves two-way trade with the domestic firm picking $q_{l}$ and the foreign firm $q_{h}$. These goods sell at prices:

$$
p_{l}=\left(\frac{m+1}{m+(\lambda / U)}\right) \frac{\lambda \bar{\theta}(\mu-1)}{(4 \mu-1)} q_{l} ; p_{h}^{*}=2\left(\frac{m+1}{\left(m / U^{*}\right)+\lambda}\right) \frac{\lambda \bar{\theta}(\mu-1)}{(4 \mu-1)} q_{h}
$$

in the two countries. World demands for each firm are:

$$
D_{l}(.)+D_{l}^{*}(.)=\frac{(1+m) \mu}{4 \mu-1}
$$

and

$$
D_{h}(.)+D_{h}^{*}(.)=\frac{2(1+m) \mu}{4 \mu-1}
$$

The quality gap between the variants $\mu$ is the solution to:

$$
\frac{4\left(4 \mu^{2}-3 \mu+2\right)}{\mu^{2}(4 \mu-7)}=\frac{c^{*}}{c}\left[\frac{\left(m / U^{*}\right)+\lambda}{m+(\lambda / U)}\right]
$$

The home firm produces a good of quality

$$
q_{l}=\frac{1}{c} \frac{\lambda \bar{\theta}(m+1)^{2}}{[m+(\lambda / U)]} \frac{\mu^{2}(4 \mu-7)}{(4 \mu-1)^{3}}
$$


that is sold locally and exported to the foreign country. The foreign firm produces a good of higher quality:

$$
q_{h}=\frac{1}{c^{*}} \frac{\lambda \bar{\theta}(m+1)^{2}}{\left[\left(m / U^{*}\right)+\lambda\right]} \frac{4 \mu\left(4 \mu^{2}-3 \mu+2\right)}{(4 \mu-1)^{3}}
$$

for its own market and for exports. Obviously $\mu$ is important in the model since it represents the quality gap between firms' variants and measures the degree of product differentiation. Observe that $\mu$ is the unique solution to the third degree polynomial in (12). It depends on $\lambda, \mathrm{m}$, firms' development costs and bilateral trade uncertainties.

This trade equilibrium has a number of implications. Tirole (1988) shows that $\bar{\theta}$ is the inverse of the marginal utility of income. Hence, our assumption $0<\lambda \leq 1$ implies that foreign consumers have higher incomes on average and more sophisticated tastes. Using Khandelwal's (2010) terminology, parameter $\bar{\theta}$ reflects the foreign consumers largest valuation for quality and is therefore related to the concept of long quality ladder, $\lambda \bar{\theta}$ to that of short quality ladder. There are similarities with other parts of the empirical literature as well. Like in Bastos and Silva (2010), Manova and Zhang (2012), a direct comparison of (10) and (11) shows that producers of high quality have higher outputs, more precisely twice as high. From (9), it turns out that high-quality products command higher prices as long as the gap between $U$ and $U^{*}$ is not extreme. Producers vary their prices across export destinations for various $\left((\lambda, \bar{\theta}, m)\right.$ combinations. Clearly from $(9)$, export prices $p_{h}^{*}$ and $p_{l}$ do not measure absolute qualities. Conditional on prices, different combinations of parameter values lead to different quality levels. In contrast, the ratio of prices is proportional to relative quality levels:

Proposition 2 With endogenous qualities, the ratio of high quality to low quality is:

$$
\frac{q_{l}}{q_{h}}=\frac{p_{l}}{p_{h}^{*}}\left\{\frac{2(m+(\lambda / U))}{\left(m / U^{*}\right)+\lambda}\right\}<1
$$

Specifically, relative product qualities in the trade equilibrium are log-linear in relative export prices.

Thus, controlling for $m, \lambda, U$ and $U^{*}$ which are variables and parameters that can be constructed, measures of relative product quality can be obtained from relative export prices which are readily available. Note that when $U=U^{*}=1, q_{l} / q_{h}=2 p_{l} / p_{h}^{*}<1$.

\subsection{Entry-Exit Conditions}

Surprisingly total world demands for both goods in (10) and (11) do not depend on country uncertainties, only indirectly via the extent of product differentiation. There is intra-industry trade in vertically differentiated goods as long as individual export volumes $D_{l}^{*}$ and $D_{h}$ remain positive. Particularly:

$$
\begin{gathered}
D_{l}^{*}=\lambda(m+1)\left(\frac{\mu}{4 \mu-1}\right)\left\{\frac{2 U^{*}}{m+\lambda U^{*}}-\frac{1}{m U+\lambda}\right\} \geq 0 \\
D_{h}=\left(\frac{2 m \mu}{4 \mu-1}\right)-\left(\frac{m}{4 \mu-1}\right)\left\{\frac{2 \mu\left(1-\lambda U^{*}\right)}{m+\lambda U^{*}}+\frac{\lambda-U}{m U+\lambda}\right\} \geq 0
\end{gathered}
$$


Clearly these expressions can be non-positive for reasons related to $U, U^{*}, \lambda, m$ and $\mu$. There are thus incentives for firms to exit and re-enter their export markets. More formally, there are two other Nash equilibria where one of the two firms stops exporting. For example the next proposition gives conditions under which the firm of the poorer country exits its export market:

Proposition 3 There exists a Nash equilibrium with the following characteristics: (i) it is optimal for the home firm to produce the low-quality variant but to stop exporting when the following condition is satisfied:

$$
U<\frac{\lambda m}{2 m+1}
$$

(ii) in the same equilibrium, the foreign firm continues to produce high quality and export to the home country if:

$$
\frac{1}{\lambda} \frac{(4 \mu-1)}{4(\mu-1)} \leq U^{*}
$$

The proof of Proposition 3 is outlined in the Appendix, together with additional insights. ${ }^{4}$ Conditions (18) and (19) state the necessary conditions for a stable Nash equilibrium when the home firm exits its export market. They establish bounds for expected uncertainty in terms of model parameters and variables. The former states an upper limit for the expected uncertainty faced by local exporters. When the home firm exits its export market, it avoids the anti-dumping price constraint imposed by the WTO and the bilateral uncertainties involved in trade. Condition (18) in Proposition 3 differs from (16), though they are observationally equivalent. They determine a timing of exits that may arrive sooner based on expected profits. Condition (19) compares $U^{*}$ to a combination of parameters involving $\lambda$ and the degree of competition $\mu$. This condition is always satisfied with $U^{*} \rightarrow \infty$. More specifically, with $U^{*}>1$, the foreign firm derives higher profits than in a monopoly when expectations are favorable to foreign exports into the home economy.

Some monotonicity results that can be verified from these two conditions are reported in Table 1 and should be interpreted as follows. Suppose that an increase occurs in one of the model parameters of the first row, then the sign of the comparative statics of this change on either condition (18) or condition (19) is given in each relevant cell. A positive sign (negative) indicates that the condition is more (less) likely to hold. Given this, the third row shows the expected sign of each variable in the empirical analysis of the likelihood of exporting firm exits.

Table 1: Monotonicity Results for Conditions (18) and (19) $)^{(i)}$

\begin{tabular}{c|c|c|c|c|c|c|c|c|c|c}
\hline & $m$ & $\lambda$ & $E \tilde{e}$ & $E \tilde{r}$ & $E \tilde{\tau}$ & $E \tilde{\tau}^{*}$ & $\sigma_{e}^{2}$ & $\sigma_{r}^{2}$ & $\sigma_{\tau^{*}}^{2}$ & $\sigma_{\tau}^{2}$ \\
\hline $\operatorname{Cond}(18)$ & + & + & - & + & 0 & + & 0 & 0 & 0 & 0 \\
\hline $\operatorname{Cond}(19)^{(i i)}$ & 0 & + & - & - & - & 0 & + & 0 & 0 & 0 \\
\hline Exit & + & + & - & $?$ & - & + & + & 0 & 0 & 0 \\
\hline
\end{tabular}

Notes: (i) Signs are obtained by computing the first and second derivative of $U$ and $U^{*}$ while assuming independence of random variables; (ii) Changes in model parameters of the first row are assumed to be larger that $U^{*}$ than the indirect effects on competition variable $\mu$ in (12)

\footnotetext{
${ }^{4}$ The Appendix describes also the parameter space of the third Nash equilibrium of the export game, namely when the foreign firm produces high quality but stop exporting while the home firm produces low quality and exports.
} 
Regarding the task of finding proxies for expected uncertainties $U$ and $U^{*}$, we approach this problem from the perspective of independent random shocks. We compute first and second derivatives of function $U$ and $U^{*}$ whose results are reproduced in Table 1 while assuming zero co-movement of stochastic variables. For example, $U^{*}$ is convex in $\tilde{e}$ as its second derivative is positive everywhere. In contrast, the volatility of other variables are zero as both $U$ and $U^{*}$ are linear functions of these three variables. For $E \tilde{r}$ the sign is ambiguous and thus becomes an empirical question.

\subsection{Higher Dimensions}

The theoretical framework thus far describes the market for a vertically differentiated product where a domestic firm, located in a developing country with less and poorer potential buyers, supplies its own market while facing import competition from a foreign firm. It also exports to a larger and richer country where it faces competition from the same foreign firm. Because of the WTO's antidumping constraint, the local firm's foreign price depends on that at home.

The transition to our data analysis gives rise to the dimensionality issue: can the results of our simple theoretical framework serve as a suitable tool to interpret the high-dimensional data of our sample? In our empirical work, Philippine exporters face about the same foreign competitors at home and abroad, a feature of the global economy. At this level of disaggregation, most entry-exit decisions are bilateral, namely destination-specific. Regarding quality measures, the logic of proposition 2 stays valid with higher dimensions. The reason is that the two-stage maximization of the model includes two sets of best response functions, in prices and in qualities. As expressions for aggregate demands in (1) include qualities, best response functions in prices contain qualities as well. Even with more firms (hence products and destinations) prices are function of qualities and relative prices are a function of relative qualities though the relationship might be non-linear. Regarding exit conditions, deviations are analytically more difficult to compute as the number of firms increases and remain an empirical question.

\section{Data Sources and Methods}

In the next section we investigate the empirical determinants of the survival of Philippine exporters to numerous foreign destinations using the model outlined above as guide. We first describe the data, outline our estimation techniques and define the explanatory variables. Later we present empirical results.

\subsection{Data Description}

Our dataset consists of the universe of import and export data from 1991-2012 matched with 13 annual manufacturing surveys spanning the period 1996-2012. However we restrict our data to the period 1996-2007..$^{5}$ The period before 1995 firm names are sometimes missing and temporary trader code are given therefore the first 5 five years are dropped. Due to missing data on transportation cost

\footnotetext{
${ }^{5}$ The data of other periods also used. For example unlike most survival regression our data can determine whether a spell truly starts in 1996 or is left censored but also whether a spell stops in 2007 or is right censored. Therefore unlike most survival regressions we have two extra years in terms of information.
} 
after 2007 they are left out of the analysis. But most importantly the majority (9 surveys) and the most important surveys in terms of observations are covered in this period. The trade commodity classification is detailed as the PSCC (Philippine Standard Commodity Classification) is at the 7-digit level and corresponds until the $5 t h$ digit with the SITC (Standard International Trade Classification) Rev. 3. Three main corrections are applied to the data before use. Firstly, firms that are not directly involved with the production of the product they export are dropped. ${ }^{6}$ Secondly, observations that in real terms had a value worth less than $\$ 1000$ were dropped from the sample. Lastly, Product categories that cannot be linked directly to firms or domestic production are also deleted from the analysis (See Appendix B for more information about the data sources). ${ }^{7}$

After the necessary corrections our data consist of 390,859 firm-product-destination (FPD) observations and a total of 244,533 spells. These spells come from a total of 5,472 firms of which 2,561 firms are present on average every year in the sample. However due to difficulties of obtaining extra data for certain products and destinations the data sample differs per model specification. In the dataset there are a total of 250 destinations to which firms export. However due to data constraints we analyze 181 destinations of which the most are countries (See Appendix D for list of destinations in data). On average the manufacturing firms export to 117 destinations per year. A large portion of these spells have as destination the USA (18.6\%), EU (16.8\%) or Japan (9.2\%). Besides Japan, regional trade is also of importance as countries such as South Korea (2.6\%), Hong Kong (4.7\%), Taiwan (3.4\%), China (2.7\%) and ASEAN (11.8\%) member countries (especially Singapore, Thailand and Malaysia) have become increasingly important destinations for firm export spells. The firms in the sample export 5,048 different products and on average 2,308 products per year. ${ }^{8}$ Altogether the firms in the sample export 6.8 products to 5.6 destinations on average per year. ${ }^{9}$ Therefore the sample consists mostly of relatively large firms.

\subsection{Econometric Methods}

Survival analysis models the waiting time to the occurrence of an event. In our framework an event is firm exit, namely when firm $\mathrm{f}$ stops exporting product $\mathrm{p}$ to destination $\mathrm{d}$ at date $\mathrm{t}$. This event is observed if one of the following three conditions arises: (1) a firm ceases to export a product to a destination; (2) it stops exporting the product; (3) the firm quits exporting altogether. The analysis attempts to answer questions of the type: What is the proportion of manufacturing firms that will keep exporting to foreign destinations past a certain time? At what rate will they exit? What is the contribution of explanatory variables to the probability of exits?

Specifically we employ the discrete-time survival method which among others specifies a discretetime hazard function $h_{t}$. It is the conditional probability that a firm stops exporting a product to a destination at time $t$, given that it has not occurred before. Denote by $\mathrm{T}$ the time it takes before an

\footnotetext{
${ }^{6}$ Similar to Manova and Zhang (2012) firms that had in their name the following words Export, Import, Trader, Trading, Logistic, Shipping and Moving are deleted from the sample

${ }^{7}$ Product categories Good returned to the country whence exported, other commodities temporarily imported/exported, personal and household effects of travel and replacement of returned good are examples of product categories that should not appear in the analysis. These product categories comprise most of the products that form the category 93 in the PSCC classification. Therefore all observations that are linked to Pscc division 93 (with the notable exception of PSCC items 93101 till 93102 which contains products built on consignment basis).

${ }^{8}$ For the first regression the total number of exported products drop to 4,846 and on average 2,204 products per year

${ }^{9}$ This calculation includes firm observations of products and destinations that are left censored
} 
export spell stops, which in our sample can take the values $t=1,2,12$. Formally:

$$
h_{t}=P(T=t \mid T \geq t-1)
$$

Figure 3 displays the estimated exit rate for each year based on the entire population of firms. In contrast to the existing literature exit rates are high in the first three years but low thereafter. In year one, $72.2 \%$ of trade relationships do not survive to the second year. In year two, from those firms that survive, $45.6 \%$ stop in the second year. By year four about $20 \%$ of trade transactions do not survive to the next year, implying high survival rates from then on. Clearly export spells have a short duration, the mean being 20 months. ${ }^{10}$

Figure 3: Discrete-time hazard

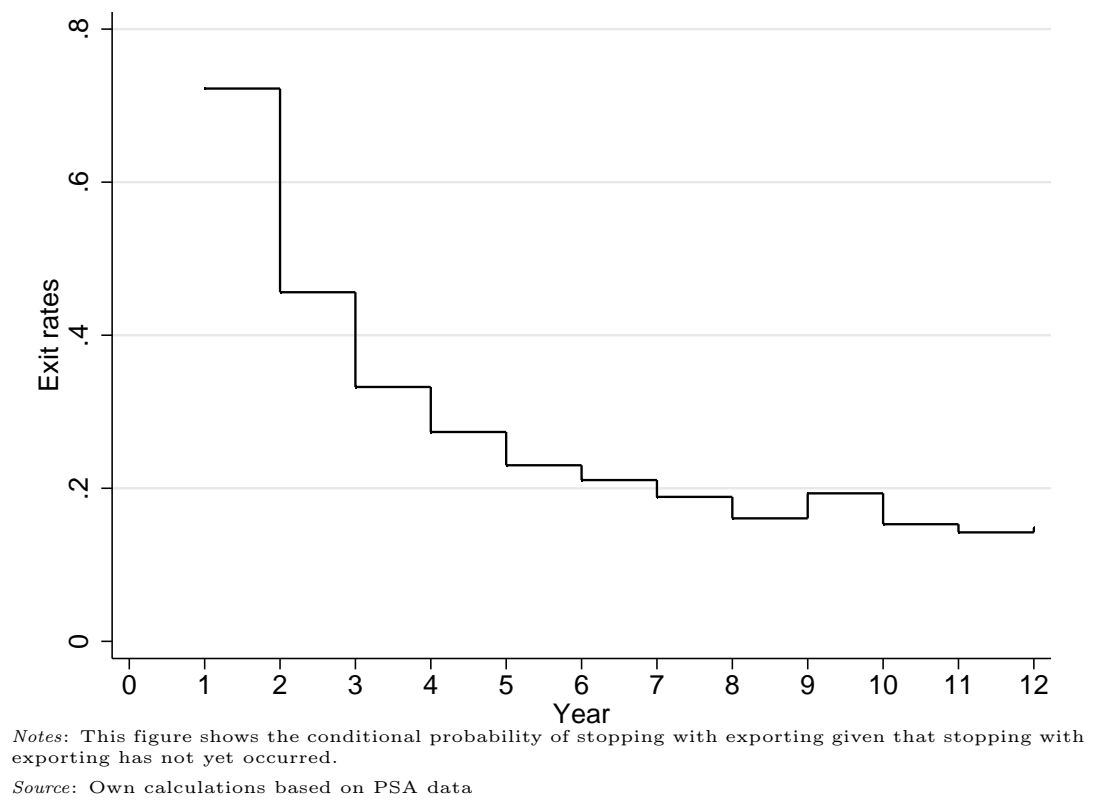

The dependent variable of our empirical method is binary and indicates whether an exporting firm is present in a foreign market or not. Particularly, the observed outcome for each firm-productdestination-year is coded 1 if the firm exits the market in that year; otherwise it is coded 0 . For simplicity, let $g=(f, p, d)$ group the subscripts of the model except for time $\mathrm{t}$ and let $y_{g t}$ define the observed outcome. The probabilities can be confined between 0 and 1 by using a non-linear model of the type: $P\left[y_{g t}=1\right]=F\left(\mathbf{D}_{g t} \alpha+\mathbf{X}_{g t} \beta\right)$ where the function $F($.$) has values ranging between 0$ and 1 and is monotonically non-decreasing. A popular choice for $F($.$) is the logistic function:$

$$
P\left[y_{g t}=1\right]=\frac{1}{1+e^{-\left(\mathbf{D}_{g t} \alpha+\mathbf{X}_{g t} \beta\right)}}
$$

The independent variables consists of several groups: matrix $\mathbf{G}_{g t}$ contains duration dummies $(2,3, \ldots$,

\footnotetext{
${ }^{10} \mathrm{~A}$ comparison with the existing literature is difficult to make as Besedes and Prusa (2006) consider product survival spells (thus not firm specific as in our study) and Cadot et al. (2013) consider one-period survivals. For example, product survival rates for differentiated products in Besedes and Prusa (2006) are quite high in the first three years to drop to about $50 \%$ thereafter.
} 
12) that transform the logistic model into a discrete logistic survival model; matrix $\mathbf{X}_{g t}$ includes the constant and independent variables that may be continuous or categorical; $\alpha$ and $\beta$ are the corresponding vectors of unknown parameters. A transformation of (21) leads to the Logit regression equation:

$$
\ln \left\{\frac{P\left[y_{g t}=1\right]}{1-P\left[y_{g t}=1\right]}\right\}=\mathbf{D}_{g t} \alpha+\mathbf{X}_{g t} \beta+\varepsilon_{g t}
$$

where $\varepsilon_{g t}$ is a vector of unobserved disturbances.

The coding of observations into ones and zeros gives rises to a number of remarks regarding the construction and interpretation of the left-hand side of (21) and (22). A first issue is related to the arbitrariness in the selection of any sample, 1996-2007 in our case. Observations are right-censored because though some firms might have entered new export markets at some date our study ends before their exit is observed. We partially cope with censoring by checking firms export status in 2008 and modify the 2007 codes accordingly. In contrast, our observations are not left-censored as the study only considers export spells from 1996 onward. Secondly, exports are recorded on a yearly basis while exit time is continuous. By using discrete survival data we thus deal with fewer integer survival times that are shared by many. This is a case of interval censoring where the timing of events is partially known. Finally, in the data some firms experience discontinuous exporting spells of the same product to the same destination. Given this, the analysis uses gap time formulation in which case the clock is reset to zero for a firm every time an exporting spell ends. The data coding gives thus limited credit for the experience that has been gained by exporting. ${ }^{11}$

A number of methodological issues have guided our choice of estimation technique. First, we deviate from the proportionality assumption imposed by Cox models, where the effect of the explanatory variables is deemed constant over time. As Hess and Persson (2012) and Brenton et al. (2009) argue, such an assumption does not hold for trade data. We therefore opt for Logit regressions because such strict proportionality assumption is not imposed. Second, our estimation method has to account for unmeasured heterogeneity, a stylized fact linked to a selection process that is typical of firm microdata. In the presence of such heterogeneity survival patterns for the entire population of firms are entirely different from those of an individual firm. If firms differ in unobserved ways in their inherent probability of failure (some firms being more robust than others), then a selection process takes place. This is the so-called frailty effect which our estimation method will account for. ${ }^{12}$ Specifically, we use a random effects model where frailties are no longer observation specific but instead are shared across groups of observations, thus causing those variables to be correlated. This is captured by a firm specific random intercept $\zeta_{f} \sim \tilde{N}(0, \psi)$, identically distributed across firms and independent of covariates. ${ }^{13}$

\subsection{Construction of Variables}

In our econometric specifications, the dependent variable is binary, where it can take a value 1 if the Philippine exporter $f$ of a product $p$ at date $t$ stops exporting to a destination $d$, a value 0 if the same

\footnotetext{
${ }^{11}$ One could have chosen the counting process formulation instead. However, we obtain results similar to those using gap time formulation. Moreover explanatory variables capturing experience and learning by exporting are introduced in our estimated models.

${ }^{12}$ The frailty effect ensures that regardless of the shape of individual hazards, the population hazard declines over time.

${ }^{13}$ For a more complete review of random effects in survival models, see Skrondal and Rabe-Hesketh (2012).
} 
exports survive. The probability of the binary response is based on a first set of independent variables that are described in Table 2. The purpose of this table is to specify a central equation that derives from our main theoretical results. Expected signs are shown in the last row of Table 1.

The first independent variable is relative export prices of Philippine firms. As can be derived from (15) in Proposition 2, relative prices $\left(p_{l} / p_{h}^{*}\right)$ are related to relative quality $\left(q_{l} / q_{h}\right)$. Thus besides measuring the relative competitiveness of firms in destination markets, relative prices are at the same time an imperfect proxy for relative quality. Export prices are computed in two ways: (1) relative to the average export price of foreign exporters to the Philippines within the same product category; (2) relative to the median export price of the same foreign exporters to the Philippines. In the estimation equations, we define relative export prices both in $\operatorname{logs}\left(\ln p_{l} / p_{h}^{*}\right)$ and in quintiles on the ranked set of relative export prices (rlxprice(.)). The latter specification is intended to capture the nonlinearity of the effects on survival but also to mitigate issues related to the endogeneity of prices and/or comovement with other explanatory variables. The relative number of potential consumers $m$ for any product is proxied by the Philippine population divided by destination population ( lipc). The relative income parameter $\lambda$ is proxied by relative real incomes per capita, that of the Philippines relative to destination (rlpop).

Expected uncertainties of our random variables enter regressions in two ways, through a level effect and a risk effect. The level effect of exchange rates is captured by the real bilateral exchange rate of the pesos with respect to destination currency. To abstract from currency units, the real exchange rate is expressed as the expected depreciation rate of the pesos (reer). The risk effect is proxied by the rolling coefficient of variation of the bilateral exchange rates with a rolling window of 5 years $((u n c(\tilde{e}))$. Transport costs are measured by iceberg rates (iceberg). Transport cost uncertainty is proxied by the median of percentage changes in transport costs of all products a firm exports between date $t$ and date t-1(uncr $(\tilde{r}))$. Regarding trade policy uncertainty, the level effect is captured by the simple average of applied tariffs. As most independent variables are expressed in relative terms, we include the difference between the destination average and the Philippine average (tariff $f^{*}$-tariff). The risk effect is approximated by the normalized difference in the rule of law scores between destination and the Philippines $(u n c(\tilde{\tau}))$. ${ }^{14}$ Finally, Consign stands for consignment trade. ${ }^{15}$ It is a popular trade practice in the Philippines whereby payments to the exporters are sent only after goods are sold by the foreign distributor. This activity is recorded in SITC-93 (special transactions) categories.

Table 2 defines explanatory variables that further control for other firm-, destination-, and industryspecific characteristics or attributes. Though it is a model variable R\&D is included here because its inclusion is very costly in terms of observations. R\&D expenditures at the firm level give an approximation of product quality development cost, namely the extent to which firms are able to reduce the marginal cost of quality development $c$. Firm data are only available for the small subset of Philippine firms, namely those sampled in surveys. However, this loss in observations is limited if we aggregate yes/no responses to 5 -digits ISIC . Another explanatory variable is distance (Dist) and the interaction term with a quintile measure of transport costs(Trans(.)). We expect the sign of

\footnotetext{
${ }^{14}$ As firms are forward looking, they develop expectations regarding the conditional distribution of each random variable. To proxy this distribution, we assume perfect foresight and lead the level and risk variables by one-period (date $t+1)$. Particularly, this is done for exchange rates as data are year averages. In contrast, this is not necessary for transport costs and tariffs as they are end-of-year observations.

${ }^{15}$ The various payment techniques are listed in www.export.gov, whose main goal is to help U.S. companies export.
} 
transport costs and distance, measured separately, to be positive and thus adding to the probability of exit. However, the interaction terms should produce the opposite sign: higher transport costs due to longer distance travelled should increase the duration of exports. ${ }^{16}$

Besides destination characteristics, firm characteristics are added to test for size and learning by exporting. Size is represented by a binary variable that takes value 1 when a firm has 200 or more employees (Emp200). Learning by exporting is represented by the dummy variable Experience(.)that reflects the number of export spells a firm experienced prior to any date t. The inexperience of firms is characterized by two variables, namely FirstTimeProduct and FirstTimeDestination. The former indicates that the firm just started to export a new product p. The latter characterizes a firm exporting an existing product to a new destination. Finally the covariate Networkef fect measures the extent by which Philippine firms abroad benefit from each other, and proxied by the number of firms active in any particular market. ${ }^{17}$ See the Appendix for further details regarding the definition, construction and sources of data.

\footnotetext{
${ }^{16}$ This expectation is derived from the premise that the longevity of firms is proxied by their ability to supply destinations that are farther away, and typically with higher quality goods (Hallack, 2006).

${ }^{17}$ The notion that export firms of a particular nation can gain from exchanging information about destination markets is contained in the theoretical contribution by Krautheim (2012).
} 
Table 2: Central estimation variables

\begin{tabular}{|c|c|}
\hline Variable Name & Description \\
\hline \multicolumn{2}{|r|}{ Relative export price $\left(p_{l} / p_{h}^{*}\right)$} \\
\hline lnrlxprice $_{m d, f p d t}$ & $\begin{array}{l}\text { log of the US } \$ \text { price of firm } f \text { exporting product } p \text { to destination } d \text { at } \\
\text { time } t \text { relative to the median US } \$ \text { price of the same product imported } \\
\text { into the Philippines. }{ }^{(i)(i i)}\end{array}$ \\
\hline lnrlxprice $_{m, f p d t}$ & $\begin{array}{l}\log \text { of the US } \$ \text { price of firm } f \text { exporting product } p \text { to destination } d \text { at } \\
\text { time } t \text { relative to the mean US } \$ \text { price of the same product imported into } \\
\text { the Philippines. }{ }^{(i)(i i)}\end{array}$ \\
\hline rlxprice $(0)_{m d, f p d t}$ & $\begin{array}{l}1 \text { when the US } \$ \text { price of firm } f \text { exporting product } p \text { to destination } d \text { at } \\
\text { time } t \text { relative to the median US } \$ \text { price of the same product imported } \\
\text { into the Philippines falls within the interval }[0,0.6] ; 0 \text { otherwise. }{ }^{(i)(i i)}\end{array}$ \\
\hline rlxprice $(1)_{m d, f p d t}$ & 1 when the same relative export price falls within $(0.6,1] ; 0$ otherwise \\
\hline rlxprice $(2)_{m d, f p d t}$ & 1 when the same relative export price falls within $(1,1.6]$; 0 otherwise \\
\hline rlxprice $(3)_{m d, f p d t}$ & 1 when the same relative export price falls within $(1.6,4] ; 0$ otherwise \\
\hline rlxprice $(4)_{m d, f p d t}$ & 1 when the same relative export price falls within $(4, \infty) ; 0$ otherwise \\
\hline rlxprice $(0)_{m, f p d t}$ & $\begin{array}{l}1 \text { when the US } \$ \text { price of firm } f \text { exporting product } p \text { to destination } d \text { at } \\
\text { time } t \text { relative to the mean US } \$ \text { price of the same product imported into } \\
\text { the Philippines falls within the interval }[0,0.3] ; 0 \text { otherwise. }{ }^{(i)(i i)}\end{array}$ \\
\hline rlxprice $(1)_{m, f p d t}$ & 1 when the same relative export price falls within $(0.3,0.7] ; 0$ otherwise \\
\hline rlxprice $(2)_{m, f p d t}$ & 1 when the same relative export price falls within $(0.7,1] ; 0$ otherwise \\
\hline rlxprice $(3)_{m, f p d t}$ & 1 when the same relative export price falls within $(1,1.72] ; 0$ otherwise \\
\hline rlxprice $(4)_{m, f p d t}$ & 1 when the same relative export price falls within $(1.72, \infty) ; 0$ otherwise \\
\hline \multicolumn{2}{|r|}{ Proxy for model variables } \\
\hline $\operatorname{lnrlpop} d, t$ & $\begin{array}{l}\text { log of Philippine population as a ratio of population of destination } \mathrm{d} \text {, } \\
\text { the latter being a proxy for } m\end{array}$ \\
\hline $\operatorname{lnrlipc_{d,t}}$ & $\begin{array}{l}\text { log of Philippine income per capita as a ratio of income per capita of } \\
\text { destination } d \text {, the latter being a proxy for } \lambda\end{array}$ \\
\hline reer $_{d, t+1}$ & $\begin{array}{l}\text { proxy for } E \tilde{e} \text {; the percentage change in the real bilateral exchange rate } \\
\text { expressed as real pesos per unit of real destination currency from } t \text { to } \\
t+1\end{array}$ \\
\hline iceberg $_{f, p, d . t}$ & $\begin{array}{l}\text { proxy for } E \tilde{r} \text {; US } \$ \text { unitary transport cost as a proportion of received } \\
\text { US } \$ \text { export price by firm } f \text { for product } p \text { to destination } d\end{array}$ \\
\hline $\operatorname{tarif} f_{d, t}^{*}$ & proxy for $E \tilde{\tau}^{*} ;$ Simple average of applied tariffs in destination d \\
\hline $\operatorname{tarif} f_{t}$ & proxy for $E \tilde{\tau}$; Simple average of applied tariffs in the Philippines \\
\hline$u n c(\tilde{e})_{d, t+1}$ & $\begin{array}{l}\text { proxy for exchange rate uncertainty } \sigma_{e}^{2} \text {; rolling coefficient of varia- } \\
\text { tion of the nominal pesos per unit of destination currency (rolling } \\
\text { window of } 5 \text { years } t-3 \text { till } t+1 \text { ) }\end{array}$ \\
\hline$u n c(\tilde{r})_{f, p, d, t}$ & $\begin{array}{l}\text { proxy for transport cost uncertainty } \sigma_{r}^{2} \text {; The median percentage } \\
\text { change in transport costs of all products that firms export in both } \\
\text { periods } t-1 \text { and } t \text { to destination } d\end{array}$ \\
\hline$u n c\left(\tilde{\tau}^{*}\right)_{d, t}$ & $\begin{array}{l}\text { proxy for foreign trade policy uncertainty } \sigma_{\tau^{*}}^{2} \text {; index of rule of } \\
\text { law coefficient (normalized) of destination relative to that of the } \\
\text { Philippines }\end{array}$ \\
\hline$u n c(\tilde{\tau})_{t}$ & $\begin{array}{l}\text { oxy for Philippine trade policy uncertainty } \sigma_{\tau}^{2} \text {; gap between bound } \\
\text { riff and applied tariff }\end{array}$ \\
\hline
\end{tabular}

Notes: (i) The imported mean price is calculated from the universe of import data. If there is no corresponding mean import price at time $t$ then the average over all the time periods for that product category is used as a proxy for the imported mean at time $t$. As not all products are imported every year.; (ii) Most consignment goods have no direct corresponding import category in terms of product code. There are, however, 13 extra consignment products, consisting of clothing, footwear, gloves and mittens, brassieres, semi-conductors and watches, that could be added due to matching to articles not manufactured on consignment basis. (Mostly PSCC categories 842 and 844 ) The simple average (median) of the import prices of these corresponding products were used as proxies for the consignment goods. 
Table 3: Destination, firm and industry characteristics

\begin{tabular}{|c|c|}
\hline \multirow[t]{2}{*}{ Variable Name } & Description \\
\hline & Additional model variable \\
\hline$R \& D_{i, t}$ & $\begin{array}{l}\text { proxy for a reduction in the marginal cost of quality development c; The } \\
\text { percentage of firms within a } 5 \text {-digit PSIC section that respond in the } \\
\text { manufacturing survey that it invests in R\&D. Therefore } 1 \text { indicates that } \\
\text { all the firms with a } 5 \text {-digit PSIC section that responded to the survey } \\
\text { indicated that they invested in R\&D. }\end{array}$ \\
\hline \multicolumn{2}{|r|}{ Destination variables } \\
\hline $\operatorname{Trans}(0)_{m d, f p d t}$ & $\begin{array}{l}1 \text { when the gross kilo transport cost of firm } \mathrm{f} \text { exporting product } \mathrm{p} \text { to } \\
\text { destination } \mathrm{d} \text { at time } \mathrm{t} \text { relative to the median gross kilo transport cost } \\
\text { of the same product exported by the Philippines falls within the interval } \\
{[0,0.70] ; 0 \text { otherwise. }}\end{array}$ \\
\hline $\operatorname{Trans}(1)_{m d, f p d t}$ & 1 when the same relative transport costs falls within $(0.70,1] ; 0$ otherwise \\
\hline $\operatorname{Trans}(2)_{m d, f p d t}$ & 1 when the same relative transport costs falls within $(1,1.61] ; 0$ otherwise \\
\hline $\operatorname{Trans}(3)_{m d, f p d t}$ & 1 when the same relative transport costs falls within $(1.61, \infty) ; 0$ otherwise \\
\hline $\operatorname{lnDist}_{d}$ & $\begin{array}{l}\text { The natural logarithm of the great circle distance between the } \\
\text { capital city of the Philippines and that of the respective destina- } \\
\text { tion. If the destination had no capital city then the largest city is } \\
\text { taken. }\end{array}$ \\
\hline \multicolumn{2}{|r|}{ Firm characteristics } \\
\hline $\operatorname{Emp} 200_{f t}$ & $\begin{array}{l}\text { Dummy variable takes value } 1 \text { when a firm has } 200 \text { or more em- } \\
\text { ployees. Data is obtained from the PSA manufacturing survey } \\
\text { and interpolated for missing observations. The certainty stratum } \\
\text { of the national survey is also used. If a firm was not surveyed then } \\
\text { that firm had at least fewer than } 200 \text { employees }\end{array}$ \\
\hline Experience $(0)_{f t}$ & $\begin{array}{l}\text { Dummy variables takes the value } 1 \text { when the number of previous } \\
\text { spells is } 0 ; 0 \text { otherwise. }\end{array}$ \\
\hline Experience $(1)_{f t}$ & $\begin{array}{l}\text { Dummy variables takes the value } 1 \text { when the number of previous } \\
\text { spells is } 1 ; 0 \text { otherwise. }\end{array}$ \\
\hline Experience $(2)_{f t}$ & $\begin{array}{l}\text { Dummy variables takes the value } 1 \text { when the number of previous } \\
\text { spells is } 2 \text { or more; } 0 \text { otherwise. }\end{array}$ \\
\hline FirstTimeProduct $_{f p t}$ & $\begin{array}{l}\text { Dummy variable takes the value } 1 \text { when it is the first spell for the } \\
\text { respective firm in which it exports the product; } 0 \text { otherwise. }\end{array}$ \\
\hline FirstTimeDestination $_{f p d t}$ & $\begin{array}{l}\text { Dummy variable takes the value } 1 \text { when it is the first spell for the } \\
\text { respective firm in which it exports to the respective destination; } \\
0 \text { otherwise. }\end{array}$ \\
\hline \multicolumn{2}{|r|}{ Industry characteristics } \\
\hline lnNetworkeffect ${ }_{f p d t}$ & $\begin{array}{l}\text { The log of the number of Philippine exporters exporting a certain } \\
\text { product ( } 7 \text {-digit Pscc) to a destination. }\end{array}$ \\
\hline consign $_{f p d t}$ & $\begin{array}{l}\text { Dummy variable takes the value } 1 \text { product if produced on con- } \\
\text { sigment basis (e.g. in PSCC groups } 93101+93102) ; 0 \text { otherwise. }\end{array}$ \\
\hline
\end{tabular}




\section{Empirical Evidence}

\subsection{Main Results}

Table 4 reports the estimated coefficients for the logistic regression model for Philippine manufacturing firms' product-destination export survival. The effects of changes in relative prices, other variables linked to the theoretical model and an industry variable, consign, are tested on the likelihood of firm exit. Relative prices, as proxy of quality, are expressed relative to the mean in columns (1) and (2) and relative to the median in (3) and (4).

Table 4: Basic results

\begin{tabular}{|c|c|c|c|c|}
\hline & (1) & $(2)$ & $(3)$ & $(4)$ \\
\hline & \multicolumn{4}{|c|}{ Relative price variables } \\
\hline & \multicolumn{2}{|c|}{ Mean $(m)$} & \multicolumn{2}{|c|}{ Median (md) } \\
\hline $\operatorname{lnrlxprice}_{f p d t}$ & \multicolumn{2}{|c|}{$0.030 * * *$} & \multirow[t]{2}{*}{$0.021^{* * *}$} & \multirow[b]{2}{*}{$-0.063^{* * *}$} \\
\hline rlxprice $(1)_{f p d t}$ & \multicolumn{2}{|c|}{$-0.030^{*}$} & & \\
\hline rlxprice $(2)_{f p d t}$ & \multicolumn{3}{|c|}{$-0.049^{* * *}$} & $-0.080^{* * *}$ \\
\hline rlxprice $(3)_{f p d t}$ & \multicolumn{3}{|c|}{-0.002} & -0.023 \\
\hline \multirow{2}{*}{ rlxprice $(4)_{f p d t}$} & \multicolumn{3}{|c|}{$0.115^{* * *}$} & $0.060^{* * *}$ \\
\hline & \multicolumn{4}{|c|}{ Model variables } \\
\hline & $0.074^{* * *}$ & $0.074^{* * *}$ & $0.074^{* * *}$ & $0.074^{* * *}$ \\
\hline $\operatorname{lnrlipc_{dt}}$ & $0.076^{* * *}$ & $0.076^{* * *}$ & $0.076^{* * *}$ & $0.076^{* * *}$ \\
\hline $\operatorname{reer}_{d, t+1}$ & $-0.590^{* * *}$ & $-0.589^{* * *}$ & $-0.588^{* * *}$ & $-0.586^{* * *}$ \\
\hline iceberg $_{f p d t}$ & $0.430^{* * *}$ & $0.403^{* * *}$ & $0.406^{* * *}$ & $0.377^{* * *}$ \\
\hline $\operatorname{tarif} f_{d t}^{*}-\operatorname{tarif} f_{t}$ & $0.539^{* * *}$ & $0.552^{* * *}$ & $0.543^{* * *}$ & $0.545^{* * *}$ \\
\hline$u n c(\tilde{e})_{d, t+1}$ & $0.357^{* * *}$ & $0.359^{* * *}$ & $0.359^{* * *}$ & $0.356^{* * *}$ \\
\hline$u n c(\tilde{r})_{f p d t}$ & 0.053 & 0.053 & 0.053 & 0.053 \\
\hline$u n c\left(\tilde{\tau}^{*}\right)_{d t}$ & 0.002 & 0.002 & 0.001 & 0.001 \\
\hline \multirow{2}{*}{$\begin{array}{l}\text { consign }_{f p d t} \\
\text { Constant }\end{array}$} & $-0.081^{*}$ & $-0.071^{*}$ & $-0.102^{* *}$ & $-0.102^{* *}$ \\
\hline & $0.605^{* * *}$ & $0.584^{* * *}$ & $0.600^{* * *}$ & $0.633^{* * *}$ \\
\hline & \multicolumn{4}{|c|}{ Random Component } \\
\hline $\ln (\psi)$ & $-1.255^{* * *}$ & $-1.247^{* * *}$ & $-1.255^{* * *}$ & $-1.250^{* * *}$ \\
\hline$\rho$ & 0.080 & 0.080 & 0.080 & 0.080 \\
\hline Year dummies & Yes & Yes & Yes & Yes \\
\hline Industry dummies & Yes & Yes & Yes & Yes \\
\hline No. of Obs. 34 & 7,858 & 858 &, 858 &, 856 \\
\hline No. of Firms & 5,391 & 391 &, 391 &, 391 \\
\hline $\mathrm{AIC}$ & $08783.5 \quad 408$ & $3675.1 \quad 408$ & $8821.9 \quad 408$ & 8732.3 \\
\hline Log likeli. & $04340.7-204$ & $4283.6-204$ & $4360.0-20$ & 4312.2 \\
\hline
\end{tabular}

Results point to a positive link between firm exit and product quality changes when the latter is proxied by relative export prices expressed in logs, as shown in the first row of Table 4. However, the coefficients in the succeeding rows, when relative prices are divided into quintiles, suggest that this relationship may be non-linear. Aiming for a quality range far above the mean lowers the probability 
of survival, while firms positioned in the quality niche just below the average leads to a significant fall in hazard rates.

Virtually all coefficients of the model variables are conssitent with the theory and are significant at $p<0.001$. Higher exit rates are positively linked to $m$, proxied by ratio of Philippine population relative to that of its export partners, rlpop, and to the relative income parameter, rlinc: expected profits diminish as the size and the average income of the export market fall, thus leading to higher hazard rates. A real depreciation of the Philippine Peso, (i.e. higher reer) has a postive effect on export survival. Higher transport costs, or iceberg, as well as higher destination-specific tariff rates, on the other hand, lead to shorter exporting spells. With respect to variables linked to expected uncertainty, exchange rate variation, unc( $\tilde{e})$, is observed to have a positive and highly significant relationship with hazard rates. Uncertainty due to transport cost changes, unc $(\tilde{r})$, likewise have a positive, but insignificant effect. The same is true for the effect of uncertainty related to the foreign policy regime, unc $\left(\tilde{\tau}^{*}\right)$. Exporting spells are also more durable when products are traded on a consignment basis.

Empirical results of Table 4 lead to further comments. Using likelihood ratio tests to discern between the four models in Table 4, it is clear that we can reject the null hypothesis that one of the equations is the true model. Equation (4) is nevertheless preferred because the median price is less subject to outliers and quintiles better specify the non-linear contribution of product quality. Therefore it will the base equation for the extensions of the next table.

In Table 5, we further control for other firm-, destination-, and industry-specific characteristics or attributes. The additional effect of $R \& D$ is reported in column (1), showing that efforts to innovate are rewarded by a higher likelihood of firm survival. The effects of transport costs variation and distance is seen in column (2). As can expected, the estimated coefficients of higher transport costs and greater distance, measured separately, are positive, thus adding to the probability of exit. However, the interaction terms produce the opposite effect. Having higher transport costs relative to the median firm exporting the same product, to the same destination increases the hazard rates, but higher transport costs due to longer distance travelled do not negatively impact on survival; in fact, it raises the duration of exports.

Column (3) controls for firm-specific variables. Firms with more than 200 workers have lower hazard rates, as well as firms with prior trade experience, namely those that have previously exited and reentered. Exporting a product for the first time have lower survival rates. Interestingly, exporting to a new destination increases survival, which hints to lower sunk costs when one exports to a new market, compared to when a new product is introduced.

Column (4) adds the impact of network effects, that is, the effect of being active in an export market populated by other Philippine firms. The negative coefficient indicates the presence of such network effects in improving the export performance of firms. The relationship of exit and consignment exports is likewise included. Contrary to the results in Table 4, consign carries a positive coefficient, so that the probability of survival is lower for exports produced in consignment basis. Firms active in this category typically produce under the more favourable conditions provided in export processing zones, hence, one would instead expect a higher survival rate. However, results here show that comparing firms with the same size and experience, those that export goods in this category have higher exit rates. These firms usually have higher foreign ownership and integrated in global production networks, so results 
Table 5: Extensions

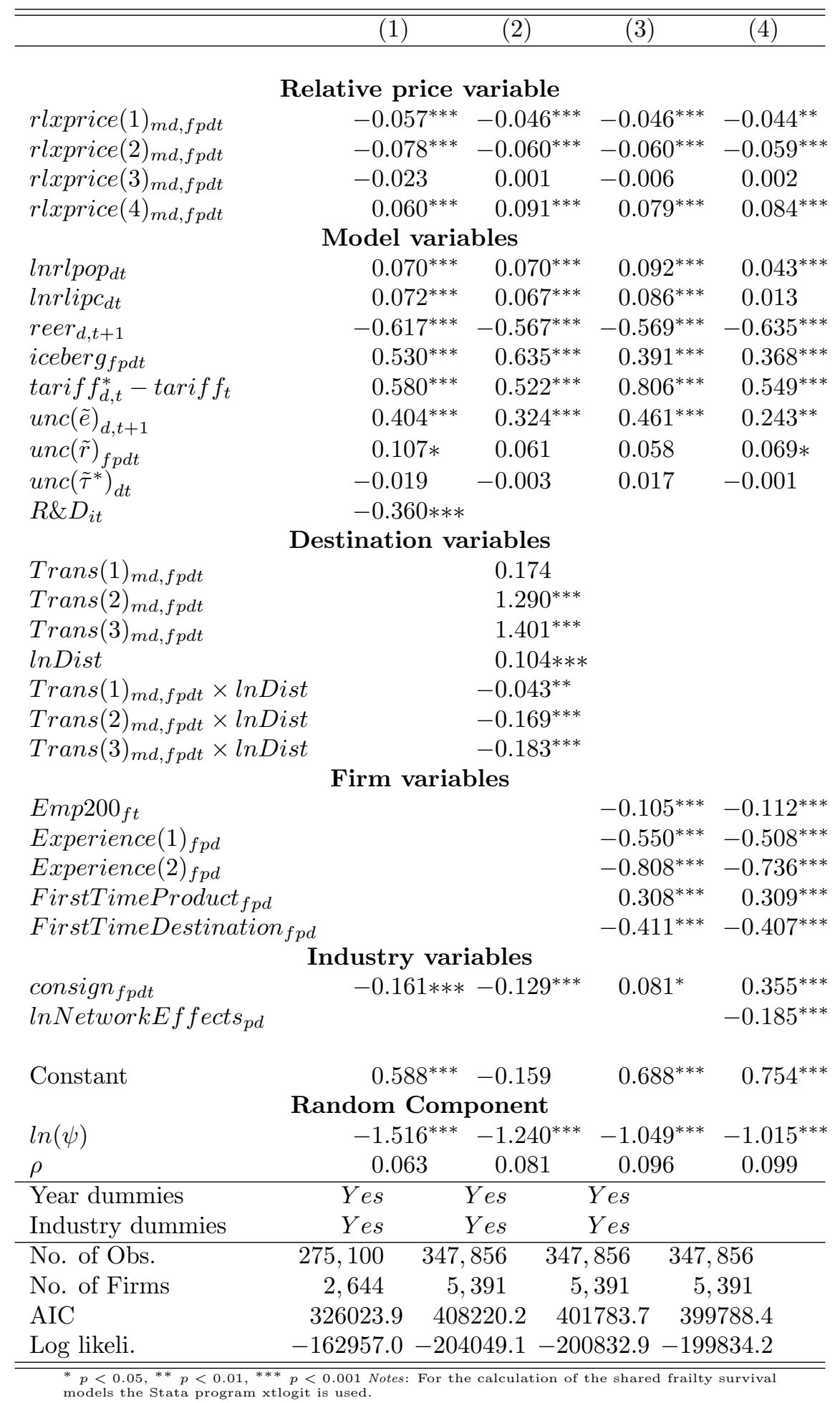


suggest that there is a higher rate of product-destination turnover for these type of firms compared to those manufacturing under more standard circumstances.

\subsection{Robustness Checks}

Alternative specifications for key variables did not change the results of Tables 4 and 5. For example, unc $(\tilde{r})_{f p d t}$ stays insignificant when it is proxied instead by the difference in transport costs between the 75 th and 25 th percentile. Likewise, $u n c\left(\tilde{\tau}^{*}\right)_{d t}$ stays insignificant as well when measured by the gap between foreign bound and applied tariff rates. Other selection problems have included different structures of fixed effect. Besides the usual industry and time fixed effects, firms heterogeneity is finally captured by random effects that turned out to be parsimonious in terms of parameter estimates and supported by a significant variance $\psi$ at $p<0.001$.

\subsection{Measurement of Product Quality}

In the Nash equilibrium with intra-product trade described in (9)-(15), absolute quality levels depend on marginal costs of quality development, parameters that are difficult to come by at the firm level. In contrast, Proposition 2 solves for relative qualities as a function of relative export prices, information that is readily available in our database. This section therefore quantifies the mapping between the distribution of relative prices and that of firms' product quality and derive Philippine firms' export quality. Given this, we are able to display firms' relative quality levels among regions and across time and, ultimately identify the domains of the distribution of relative product qualities that lead to firms' export survival.

The analysis considers product quality for any given product for which intra-product trade exits. We first identify the median foreign firm, namely the firm registered in any specific destination (e.g., the USA) that charges the median export price to the Philippines. We then search for all Philippine firms that participate in this intra-product trade with the specific destination. These situations account for 187,676 observations, or about 55 percent of our sample. Let us introduce the subscript $m d$ to denote this median exporter to the Philippines. It is useful to adapt (15) to the dimensions of our data by adding subscripts and converting prices in the same currency:

$$
\frac{q_{l ; f p d t}}{q_{h ; m d, f p d t}}=2 \Omega_{f p d t} \frac{p_{l ; f p d t}}{p_{h ; m d, f p d t}^{*} E \tilde{e}_{m d, t}}
$$

where firms' relative export quality $\left(q_{l ; f p d t} / q_{h ; m d, f p d t}\right)$ is proportional to the firms' relative $F o b$ price in foreign currency units. For any product $p$, the firms' export price $\left(p_{l ; f p d t} / E \tilde{e}_{d t}\right)$ is expressed relatively to the import price $p_{h ; m d, f p d t}^{*}$ charged by the median exporter. Hence, a single firm $f$ may export multiple product qualities to multiple destinations. This is consistent with the concept of flexible production (Eaton and Schmitt, 1994), that is, once firms invest in the necessary technology and organize their facilities to develop and produce one basic product, they can produce various downgrades of this basic product at no cost. The coefficient of proportionality depends also on all 
dimensions of our database:

$$
\Omega_{f p d t}=\left(\frac{m_{m d, t} U_{f p d t}+\lambda_{m d, t}}{m_{m d, t}+\lambda_{m d, t} U_{m d, f p d t}^{*}}\right)\left(\frac{U_{m d, f p d t}^{*} E \tilde{e}_{m d, t}}{U_{f p d t}}\right)
$$

If $E \tilde{e}_{m d, t}$ is assumed to be the actual nominal exchange rate between the Philippines and median country (index, base year 2005=100), all parameters in (25) are identifiable. For example, the various characteristics of the Philippine export firm are known, those of the median exporter to the Philippines as well. The proportion can therefore be computed using the information contained in our database. ${ }^{18}$

Equation (24) points out that relative quality is equal to relative prices multiplied by $2 \Omega_{f p d t}$. Important for our paper is whether or not relative prices have a similar ranking as relative quality. If $\Omega_{f p d t}$ does not alter the ranking then relative prices are a unbiased proxy for relative quality.

For the sake of illustration let us focus on bilateral transactions. The first step in the computations is to identify products for which intra-product bilateral trade exists. The export prices are matched to the corresponding bilateral median import prices in a given year $t$. When observations for the later are missing, its value is then interpolated by the median real value of the pooled sample of all observations for that product. Table 6 shows summary statistics on the variation in $\Omega_{f p d t}$. The total number of export observations per destination are given in column (1). As already indicated, the USA is by far the largest export partner of the Philippines.

The value of $\Omega_{f p d t}$ varies across firms and over time. The $25^{t h}, 50^{t h}$ and $75^{t h}$ percentiles of $\Omega_{f p d t}$ are displayed in columns (4), (5) and (6); the mean and standard deviation in column (7) and (8). The USA, Japan and China is notably higher than for the other destinations because of outliers. It is important to note that $\Omega_{f p d t}$ mainly contains variables that vary solely over time, except for two-way transport costs that differ across firms, products and destinations.

Table 6: Summary statistics of $\Omega_{f p d t}$ across firms in a given destination

\begin{tabular}{lcccccccc}
\hline & $\begin{array}{c}\text { \# obs. } \\
(1)\end{array}$ & $\begin{array}{c}\text { Min } \\
(2)\end{array}$ & $\begin{array}{c}\text { Max } \\
(3)\end{array}$ & $\begin{array}{c}25^{t h} \mathrm{P} . \\
(4)\end{array}$ & $\begin{array}{c}50^{\text {st }} \mathrm{P} . \\
(5)\end{array}$ & $\begin{array}{c}75^{\text {st }} \mathrm{P} . \\
(6)\end{array}$ & $\begin{array}{c}\text { Mean } \\
(7)\end{array}$ & $\begin{array}{c}\text { SD } \\
(8)\end{array}$ \\
\hline China & 10,230 & 0.916 & 44.0 & 1.055 & 1.085 & 1.160 & 1.176 & 0.804 \\
Hong Kong & 18,111 & 0.038 & 4.2 & 0.929 & 0.960 & 0.976 & 0.945 & 0.068 \\
Japan & 37,122 & 0.209 & 69.7 & 0.915 & 0.943 & 0.966 & 0.945 & 0.522 \\
Singapore & 14,534 & 0.092 & 5.5 & 0.930 & 0.962 & 0.974 & 0.944 & 0.077 \\
South Korea & 10,131 & 0.290 & 2.4 & 0.858 & 0.883 & 0.904 & 0.879 & 0.064 \\
Taiwan & 13,463 & 0.170 & 1.2 & 0.884 & 0.906 & 0.920 & 0.897 & 0.046 \\
Thailand & 9,357 & 0.124 & 3.3 & 0.873 & 0.892 & 0.916 & 0.898 & 0.066 \\
USA & 74,728 & 0.004 & 279.7 & 0.912 & 0.940 & 0.972 & 0.949 & 1.156 \\
\hline
\end{tabular}

Table 7 reports the rank correlation between the distribution of relative prices and the distribution of product quality. Rank correlations are very high, indicating that the ranking of relative prices is very similar to the ranking of quality. Hence, relative prices are a good indicator of relative quality in a bilateral setting. Even though this experiment does not extend directly to the full sample, the

\footnotetext{
${ }^{18}$ Our concepts of quality are related to those of Feenstra and Romalis (2014). It is clear from (9) that log quality is a fraction of $\log$ fob prices as in their equation (18). Analogously, to isolate quality we would have to estimate the coefficient of proportionality from demands for product varieties and cost functions for quality. However, by taking relative prices as in (24), matters simplify as (25) can be computed using data for key variables.
} 
strength of the results at the very least makes a convincing claim for the use of relative prices as a proxy for relative quality, thereby validating our approach.

Lastly, Figures 4a and 4b display the bilateral distributions of relative quality at the beginning and end of the sample for the Philippine exports to the USA and South Korea. In both panels the value zero is crucial as it denotes that the relative quality is equal, namely that the median import quality and that of export are equal bilaterally. Both figures show that the relative bilateral quality of Philippine exports has decreased over time as the distribution shifts to the left. ${ }^{19}$

Table 7: Rank correlations between the distribution of prices and the distribution of qualities

\begin{tabular}{ccc}
\hline & Spearman's $\rho$ & Kendall's $\tau$ \\
\hline China & 0.995 & 0.961 \\
Hong Kong & 0.998 & 0.980 \\
Japan & 0.998 & 0.976 \\
Singapore & 0.997 & 0.976 \\
South Korea & 0.999 & 0.980 \\
Taiwan & 0.999 & 0.983 \\
Thailand & 0.999 & 0.979 \\
USA & 0.998 & 0.970 \\
\hline
\end{tabular}

Figure 4: Distribution of bilateral relative quality

a. USA

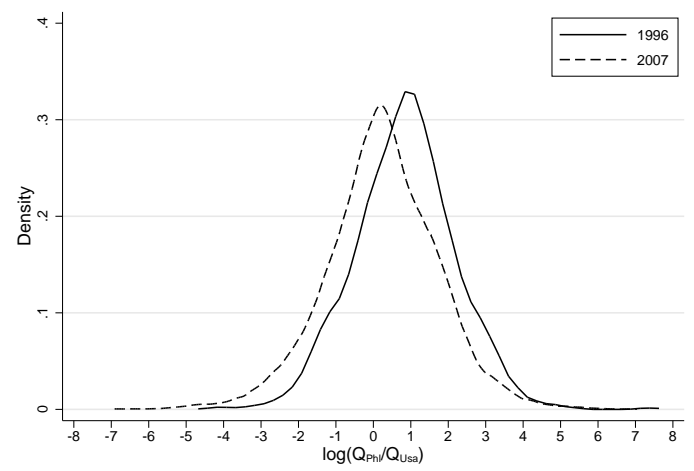

Notes: The Kernel used for the figures is Epanechnikov. b. South Korea

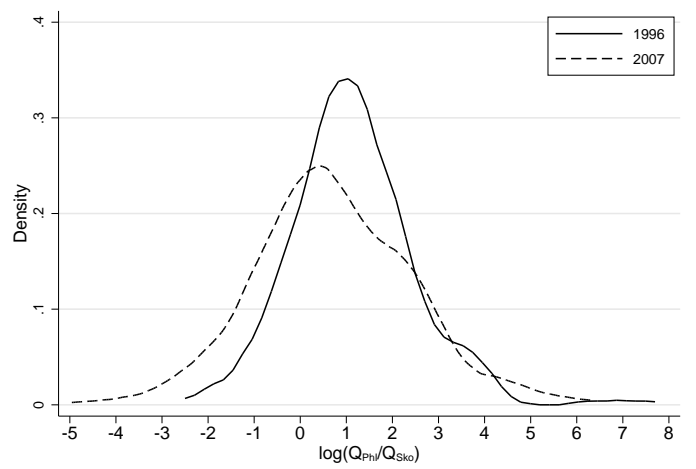

\subsection{Marginal Effects on Exit Probabilities}

Marginal effects provide useful information regarding the relative response of the dependent variable to a change in a covariate. Table 8 quantifies these responses for two models in Tables 4 (columns 1 and 4) and two models in Table 5 (columns 1 and 4) that embed different specifications. All marginal effects are statistically significant at $p<0.001$, except for the uncertainty in government policies that is never significant and that of transport cost whose p-values vary per specification.

A number of clarifications will enhance the interpretation of Table 8. It is clear that models of Tables 4 and 5 measure the probability that a firm with a number of characteristics selects to stop

\footnotetext{
${ }^{19}$ Similar conclusions can be reached for Thailand but other countries like China, Hong Kong, Taiwan, Thailand, Japan and Singapore show no change in the distribution of relative quality over time (see Appendix E.1).
} 
Table 8: Marginal Effects

\begin{tabular}{|c|c|c|c|c|}
\hline & $(4.1)$ & $(4.4)$ & $(5.1)$ & $(5.4)$ \\
\hline \multicolumn{5}{|c|}{ Relative price variable } \\
\hline & $\operatorname{Mean}(m)$ & \multirow{2}{*}{\multicolumn{3}{|c|}{ Median (md) }} \\
\hline $\operatorname{lnrlxprice~}_{f p d t}$ & $0.007^{* * *}$ & & & \\
\hline rlxprice $(1)_{f p d t}$ & & $-0.014^{* * *}$ & $-0.013^{* * *}$ & $-0.010^{* * *}$ \\
\hline rlxprice $(2)_{f p d t}$ & & $-0.019^{* * *}$ & $-0.0187^{* * *}$ & ${ }^{*}-0.014^{* * *}$ \\
\hline rlxprice $(3)_{f p d t}$ & & -0.005 & -0.005 & 0.00 \\
\hline rlxprice $(4)_{f p d t}$ & & $0.014^{* * *}$ & $0.014^{* * *}$ & $0.019^{* * *}$ \\
\hline \multicolumn{5}{|c|}{ Model variables } \\
\hline $\operatorname{lnrlpop}_{d t}$ & $0.017^{* * *}$ & $0.017^{* * *}$ & $0.016^{* * *}$ & $0.009^{* * *}$ \\
\hline $\ln r l i p c_{d t}$ & $0.018^{* * *}$ & $0.017^{* * *}$ & $0.017^{* * *}$ & 0.003 \\
\hline $\operatorname{reer}_{d, t+1}$ & $-0.135^{* * *}$ & $-0.135^{* * *}$ & $-0.146^{* * *}$ & $-0.145^{* * *}$ \\
\hline iceberg $_{f p d t}$ & $0.099^{* * *}$ & $0.086^{* * *}$ & $0.125^{* * *}$ & $0.084^{* * *}$ \\
\hline $\operatorname{tarif} f_{d, t}^{*}-\operatorname{tariff} f_{t}$ & $0.124^{* * *}$ & $0.125^{* * *}$ & $0.137^{* * *}$ & $0.125^{* * *}$ \\
\hline$u n c(\tilde{e})_{d, t+1}$ & $0.082^{* * *}$ & $0.082^{* * *}$ & $0.096^{* * *}$ & $0.055^{* * *}$ \\
\hline$u n c(\tilde{r})_{f p d t}$ & 0.012 & 0.012 & $0.025^{* * *}$ & $0.016^{*}$ \\
\hline$u n c\left(\tilde{\tau}^{*}\right)_{d t}$ & 0.00 & 0.00 & -0.004 & -0.000 \\
\hline$R \& D_{i t}$ & & & $-0.085^{* * *}$ & \\
\hline \multicolumn{5}{|c|}{ Firm variables } \\
\hline $\operatorname{Emp} 200_{f t}$ & & & & $-0.0256^{* * *}$ \\
\hline Experience $(1)_{f p d}$ & & & & $-0.118^{* * *}$ \\
\hline Experience $(2)_{f p d}$ & & & & $-0.175^{* * *}$ \\
\hline FirstTimeProduct $_{f p d}$ & & & & $0.070^{* * *}$ \\
\hline FirstTimeDestination $_{f p d}$ & & & & $-0.092^{* * *}$ \\
\hline \multicolumn{5}{|c|}{ Industry variables } \\
\hline $\operatorname{lnNetworkEffects_{pd}}$ & & & & $-0.042^{* * *}$ \\
\hline
\end{tabular}

exporting to a destination. Specifically, using specification (21), the estimated conditional probability is equal to:

$$
\hat{P}\left[y_{g t}=1\right]=\frac{1}{1+e^{-\left(\mathbf{D}_{g t} \hat{\alpha}+\mathbf{X}_{g t} \hat{\beta}\right)}}
$$

where $\hat{\alpha}$ and $\hat{\beta}$ are vectors of estimates and $g=(f, p, d)$ groups the subscripts of the model, except time. Given (25), if variable $x_{j, g t}$ is continuous, its marginal effect on this conditional probability is equal to:

$$
\frac{\partial \hat{\mathrm{P}}\left(y_{g t}=1\right)}{\partial x_{j, g t}}=\hat{\beta}_{j}\left\{\frac{e^{-\left(\mathbf{D}_{g t} \hat{\alpha}+\mathbf{X}_{g t} \hat{\beta}\right)}}{\left[1+e^{-\left(\mathbf{D}_{g t} \hat{\alpha}+\mathbf{X}_{g t} \hat{\beta}\right)}\right]^{2}}\right\}
$$

where $\hat{\beta}_{j}$ is the estimated parameter obtained in Table 4 or 5 . The term in brackets is a scale factor that arises from the non-linearity of the logistic function. Its derivative is not constant and therefore approximated at a specific initial point. ${ }^{20}$ Consider a standard deviation (SD) increase in

\footnotetext{
${ }^{20}$ In this regard, a number of assumptions are made: $(i)$ continuous explanatory variables take their mean values; $(i i)$
} 
continuous variables. Exporting to destinations with fewer potential consumers (lnrlpop) or with lower per capita incomes (lnrlipc) increases the likelihood of exit by $3.1 \%$ and $1.5 \%$ respectively, stressing the importance of demand. An 5.6\% drop in the likelihood of exit is associated with a $S D$ increase in the number of Philippine firms exporting to a destination (lnNetworkE f fects) reducing the asymmetric information problem. A sector whose number of firms performing R\&D increases by a SD has a lower exit probability of about $1.1 \%$. Other variables have marginal effects on entry/exit of about $1 \%$.

Marginal effects of binary variables are easier to derive from Table 8 . If variable $x_{j, g t}$ is a binary variable, the following discrete change is computed:

$$
\text { marginal effect of } x_{j, g t}=\hat{P}\left(y_{g t}=1 ; x_{j, g t}=1\right)-\hat{P}\left(y_{g t}=1 ; x_{j, g t}=0\right)
$$

It is the discrete change in conditional probability $\hat{P}\left(y_{g t}=1\right)$ as binary variable $x_{j, g t}$ changes from 0 to 1 , holding all other variables equal to their means. For example, switching to a high quality product (rlxprice(4)) increases the probability of exit by 1.9\%. A FirstTimeProduct increases the exit probability by about $7 \%$; FirstTimeDestination decreases the exit probability by $9.2 \%$.

\section{Conclusion}

The objective of this paper was to promote our understanding of firms' export dynamics in emerging economies where local firms face stiff foreign competition, both at home and abroad. Particularly, we have presented and tested a model of vertical product differentiation where firms in different countries produce quality-differentiated goods for their local markets and, eventually, for exports. We explore the role of product quality in affecting this export performance as well as governmental decisions related to multiple uncertainties faced by exporters like exchange rate, freight and trade policies. Some of the conditions we have assumed are related to the firms $R \& D$ productivity in attaining specific product quality levels, the relative size of potential demands, and taste differences linked to income gaps. We have shown that the export price of local firms relative to foreign competitors is proportional to relative product quality, the coefficient of proportionality being related to composite measures of uncertainties faced by traders.

Empirically, the observed exit rates of Philippine exporting firms are high in the first three years. It is therefore not surprising that the estimated hazard function reveals a short duration of export spells, the mean being 20 months. Also firms with the highest survival rate in foreign markets are found to select a product quality contained in the interval between the median and mean of the international distribution of product quality. In contrast, those choosing a quality located at both ends of this distribution have the least chance of survival. Another empirical finding is the decrease in the relative quality of their products over time in foreign markets like South Korea, Thailand and the USA.

Of course, an important issue is to establish the policy relevance of the above results. In that regard, our findings raise the following question: is the argument by which the typical Philippine "laissezfaire" mechanism gives enough incentives for firms to compete on world markets desirable? Answers

for binary variables, the mean is a weighted average, weights being the proportions of the sample associated to each category; (iii) random effects are assumed to take their mean values, namely zero. The computed value of the scale factor hovers roughly between 0.22 and 0.30 . 
to this question have been diverse, but generally there seems strong evidence against (Hausmann and Rodrik, 2003) Instead, the current policy is to design market protection schemes to induce product quality leadership via $R \& D$ productivity and knowledge accumulation. In doing so, governments have traditionally used "industrial" policy instruments like the protection of property and the quality of institutions together with promotion agencies of trade and investment as well as antidumping policy to support local firms.

Though we are enthusiastic about our framework several important features could be considered in future research. We have already discussed the contribution of firm heterogeneity in explaining trade. However, our dataset can be further exploited to explain the characteristics of first time exporters, both in terms of products and of destinations. Also, so far our empirical analysis has not explicitly isolated cases where local firms become quality leaders on international markets. Combining the time dimension of our data using relative export prices with data on policy measures and characteristics of vertically differentiated products may allow for an empirical testing of causes and timing of quality reversals. 


\section{References}

Amity, M., O. Itskhoki, and J. Konings, "Importers, Exporters, and Exchange Rate Disconnect," American Economic Review, 2014, 104, 1942-1978.

Anderton, B., "Innovation, Product Quality, Variety and Trade Performance: An Empirical Analysis of Germany and the UK," Oxford Economic Papers, 1999, 51, 152-167.

Bas, M. and V. Strauss-Kahn, "Input-trade Liberalization, Export Prices and Quality Upgrading," Journal of International Economics, 2015, 95, 250-262.

Bastos, P. and J. Silva, "The Quality of a Firm's Exports: Where you Export Matters," Journal of International Economics, 2010, 82, 99-111.

Bernard, A. B., J. B. Jensen, S. J. Redding, and P. K. Schott, "The Margins of U.S. Trade," American Economic Review (Papers and Proceedings), 2009, 99(2), 487-493.

Besedes, T. and T. J. Prusa, "Product Differentiation and Duration of US Import Trade," Journal of International Economics, 2006, 70, 339-358.

Brenton, P., C. Saborowski, and E. Uexküll, "What Explains the Low Survival Rate of Developing Country Export Flows.," World Bank Policy Research Working Paper, 2009, No 4951.

Cabrales, A., W. Garcia-Fontes, and M. Monta, "Risk Dominance Selects the Leader: An Experimental Analysis," International Journal of Industrial Oranganization, 2000, 18, 137-162.

Cadot, O., L. Iacovone, M. D. Pierola, and F. Rauch, "Succes and Failure of African Exporters," Journal of Development Economics, 2013, 101, 284-296.

Crozet, M. and H. Erkel-Rousse, "Trade Performances, Product Quality Perceptions, and the Estimation of Trade Price Elasticities," Review of International Economics, 2004, 12, 108-129.

_ , K. Head, and T. Mayer, "Quality Sorting and Trade: Firm-level Evidence for French wine," Review of Economic Studies, 2012, 79 (2), 609-644.

Di Comite, F., J. F. Thisse, and H. Vandenbussche, "Veti-zontal Differentiation in Export Markets," Journal of International Economics, 2014, 93 (1), 50-66.

Eaton, J. and S. Kortum, "Technology, Geography and Trade," Econometrica, 2002, 70 (5), 17411779 .

Feenstra, R. C., "Symmetric Pass-Through of Tariffs and Exchange Rates under Imperfect Competition," Journal of International Economics, 1989, 27, 25-45.

- and J. Romalis, "International Prices and Endogenous Quality," Quarterly Journal of Economics, 2014, 129(2), 477-527.

Fugazza, M. and A. C. Molina, "The Determinants of Trade Survival," HEID Working Paper, 2009, No. 05. 
Goldberg, P. K., A. Khandelwal, N. Pavcnik, and P. Topalova, "Trade Liberalization and International Inputs," American Economic Review, 2009, 99(2), 494-500.

Görg, H., R. Kneller, and R. Muraközy, "What Makes a Successful Exporter?," CEPR Discussion Paper, 2007, No. 6614.

Hallack, J. C., "Product Quality and the Direction of Trade," Journal of International Economics, 2006, 68, 238-265.

- and P. K. Scott, "Estimating Cross-Country Differences in Product Quality," Quaterly Journal of Economics, 2011, 126, 417-474.

Handley, K., "Exporting under Trade Policy Uncertainty: Theory and Evidence," Journal of International Economics, 2014, 94(1), 50-66.

Hausmann, R. and D. Rodrik, "Economic Development as Self-Discovery," Journal of Development Economics, 2003, 72, 603-633.

Hess, W. and M. Persson, "The Duration of Trade Revisited. Continuous-Time vs. Discrete-Time Hazard," Empirical Economics, 2012, 43, 1083-1107.

Kelly, P. J. and L. Lim, "Survival Analysis for Recurrent Event Data: An Application to Childhood Infectious Diseases," Statistics in Medicine, 2000, 19, 13-33.

Khandelwal, A., "The Long and Short (of) Quality Ladders," Review of Economic Studies, 2010, 77(4), 1450-1476.

_ , P. K. Scott, and S. J. Wei, "Trade Liberalization and Embedded Institutional Reform: Evidence from Chinese Exporters," American Economic Review, 2013, 103(6), 2169-2195.

Krautheim, S., "Heterogeneous Firms, Exporter Networks and the Effect of Distance on International trade," Journal of International Economics, 2012, 87, 27-35.

Krishna, K., "Tariffs versus Quotas with Endogeniety Quality," Journal of International Economics, 1987, 23, 97-122.

Kugler, M. and E. Verhoogen, "Prices, Plant Size and Product Quality," Review of Economic Studies, 2012, 79(1), 307-339.

Manova, K. and Z. Zhang, "Export Prices across Firms and Destinations," Quarterly Journal of Economics, 2012, 127, 379-436.

Melitz, M., "The Impact of Trade on Intra-Industry Reallocations and Aggregate Industry Productivity," Econometrica, 2003, 71, 1695-1725.

Moraga-Gonzalez, J. L. and J.-M. Viaene, "Antidumping, Quality Reversal and Intra-industry Trade," International Economic Review, 2015, 53(3), 777-803.

Motta, M., J.-F. Thisse, and A. Carbrales, "On the Persistence of Leadership or Leapfrogging in International Economics," International Economic Review, 1997, 38, 809-824. 
Nitsch, V., "Die Another Day: Duration in German Import Trade," Review of World Economics, 2009, 145, 133-154.

Rauch, J., "Network versus Markets in International Trade," Journal of International Economics, 1999, 48, 7-35.

Shaked, A. and J. Sutton, "National Oligopolies and International Trade," in H. Kierzkowski, ed., Monopolistic Compotition and Interntional Trade, Oxford: Oxford University Press, 1984.

Skrondal, A. and S. Rabe-Hesketh, Multilevel and Longitudinal Modeling Using Stata, 3rd ed., STATA Press, 2012.

Tirole, J., The Theory of Industrial Organization, MIT Press, 1988.

van den Berg, G. J., "Duration Models: Specification, Identification, and Multiple Durations," in J. J Heckman and E. Leamer, eds., Handbook of Econometrics, 2001, pp. 3381-3460.

Verhoogen, E., "Trade, Quality Upgrading, and Wage Inequality in Mexican Manufacturing Sector," Quarterly Journal of Economics, 2008, 123, 489-530. 


\section{Online Appendix}

\section{A. Proofs of Major Propositions}

\section{Risk-Dominant Nash Equilibrium}

Given the information given in the main text, we can fold the game backwards and write down as in Table A.1 the normal-form game at the choice-of-quality and export stage. It is important to note that payoffs are expressed in local units. Therefore, variables are pre- multiplied by $E \tilde{e}=\bar{e}$ when necessary:

Table A.1: Quality Strategy Profiles

\begin{tabular}{|c|c|c|c|}
\hline & \multicolumn{2}{|c|}{ Foreign Firm } \\
\hline & & $q_{h} \& X$ & $q_{l} \& \quad X$ \\
\hline 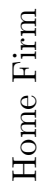 & $\begin{array}{l}q_{l} \& \quad X \\
q_{h} \& \quad X\end{array}$ & $\begin{array}{c}R_{l}-\frac{c q_{l}^{2}}{2}, \bar{e} R_{h}-\frac{\bar{e} c^{*} q_{h}^{2}}{2} \\
-\frac{c q_{h}^{2}}{2},-\frac{\bar{e} c^{*} q_{h}^{2}}{2}\end{array}$ & $\begin{array}{c}-\frac{c q_{l}^{2}}{2},-\frac{\bar{e} c^{*} q_{l}^{2}}{2} \\
\bar{e} R_{h}-\frac{c q_{h}^{2}}{2}, R_{l}-\frac{\bar{e} c^{*} q_{l}^{2}}{2}\end{array}$ \\
\hline
\end{tabular}

Let $G_{11}=R_{l}+\frac{c}{2}\left(q_{h}^{2}-q_{l}^{2}\right)$ be the gains the domestic firm obtains by predicting correctly that the foreign firm will select equilibrium $1,\left\{q_{l} \& X, q_{h} \& X\right\}$. Likewise, $G_{12}=\bar{e} R_{h}-\frac{c}{2}\left(q_{h}^{2}-q_{l}^{2}\right)$ denotes the gains the domestic firm derives by forecasting correctly that the foreign firm will select equilibrium $2,\left\{q_{h} \& X, q_{l} \& X\right\}$. Similarly, for the foreign firm we have: $G_{21}=\bar{e} R_{h}-\frac{\bar{e} c^{*}}{2}\left(q_{h}^{2}-q_{l}^{2}\right)$ and $G_{22}=$ $R_{l}+\frac{e c^{*}}{2}\left(q_{h}^{2}-q_{l}^{2}\right)$ It is said that equilibrium 1 risk-dominates equilibrium 2 when $G_{11} G_{21}>G_{12} G_{22}$. Substitution implies:

$\left(R_{l}+\frac{c}{2}\left(q_{h}^{2}-q_{l}^{2}\right)\right)\left(\bar{e} R_{h}-\frac{\bar{e} c^{*}}{2}\left(q_{h}^{2}-q_{l}^{2}\right)\right)>\left(\bar{e} R_{h}-\frac{c}{2}\left(q_{h}^{2}-q_{l}^{2}\right)\right)\left(R_{l}+\frac{\bar{e} c^{*}}{2}\left(q_{h}^{2}-q_{l}^{2}\right)\right)$

Define $Z=\frac{c}{2}\left(q_{h}^{2}-q_{l}^{2}\right)>0$ and $\gamma=\bar{e} c^{*} / c \geq 0$. Then: $\left(R_{l}+Z\right)\left(\bar{e} R_{h}-\gamma Z\right)>\left(\bar{e} R_{h}-Z\right)\left(R_{l}+\gamma Z\right)$ and $\left(\bar{e} R_{h}+R_{l}\right)(1-\gamma)>0$ This inequality holds whenever $\gamma<1$ or $c>c^{*} E \tilde{e}$.

\section{Trade Equilibrium}

The derivation of the market equilibrium starts by taking the expected value (3) and (4) and inserting constraints (7) and (8):

$$
\begin{aligned}
& E \tilde{\pi}=p_{l}\left(D_{l}+D_{l}^{*}\right)-\frac{c}{2} q_{l}^{2} \\
& E \tilde{\pi}^{*}=p_{h}^{*}\left(D_{h}+D_{h}^{*}\right)-\frac{c^{*}}{2} q_{h}^{2}
\end{aligned}
$$

Using the pair of demands in (1) and (2), taking expected values $U, U^{*}$ and quality choices $\left(q_{l}, q_{h}\right)$ as given, the problem of the domestic firm consists of finding $p_{l}$ so as to maximize $E \tilde{\pi}$ in (A.1). On the other hand, the rival foreign firm chooses $p_{h}$ to maximize its profits $E \tilde{\pi}^{*}$ in (A.1). Solving the pair of reaction functions in prices, we obtain the subgame equilibrium prices of the two variants given in $(9)$. 
Consider now firms quality selection. In this second stage, firms take expected values $U, U^{*}$ as given, anticipate the equilibrium prices of the continuation game obtained in (9), and choose their qualities to maximize reduced-form profits. Particularly, the domestic firm chooses $q_{l}$, and the foreign firm $q_{h}$ to respectively maximize:

$$
\begin{aligned}
& E \tilde{\pi}=\frac{\lambda \bar{\theta}(m+1)^{2}}{(m+\lambda / U)} \frac{\left(q_{h}^{2} q_{l}-q_{l}^{2} q_{h}\right)}{\left(4 q_{h}-q_{l}\right)^{2}}-\frac{c}{2} q_{l}^{2} \\
& E \tilde{\pi}^{*}=\frac{4 \lambda \bar{\theta}(m+1)^{2}}{\left(m / U^{*}+\lambda\right)} \frac{\left(q_{h}^{3}-q_{l} q_{h}^{2}\right)}{\left(4 q_{h}-q_{l}\right)^{2}}-\frac{c^{*}}{2} q_{h}^{2}
\end{aligned}
$$

First order conditions from the maximization of reduced-form profits (A.2) lead to the reaction functions in qualities, $q_{l}\left(q_{h}\right)$ and $q_{h}\left(q_{l}\right)$. A subgame perfect equilibrium in qualities is obtained as the solution of these two curves, namely (13) and (14). The ratio of (13) and (14) gives the third degree polynomial from which we can solve for $\mu$ in (12). After substitution we can further characterize the market equilibrium by computing, for example, world demands for goods in (10) and (11) and country demands in (15) and (16).

\section{Computation of Nash equilibria}

Let $\mathrm{X}$ and NX denote an exporting and non-exporting strategy respectively. The game played by the two firms is summarized in Table A.2. In each cell, $R\left(R^{*}\right)$ is a shorthand notation for expressions representing the expected revenues for the home (foreign) firm under four strategies $\left(s^{11}, s^{12}, s^{21}, s^{22}\right)$. Simple expressions in the table represent monopoly profits when one firm selects itself as a nonexporter. To shorten expressions, we do not write the corresponding fixed costs of quality because they are similar across strategies.

\begin{tabular}{|c|c|c|c|}
\hline & \multicolumn{2}{|c|}{ Foreign Firm } \\
\hline & & $q_{h} \& X$ & $q_{l} \& X$ \\
\hline 遠 & $q_{l} \& X$ & $E \tilde{R}_{l}\left(s^{11}\right), E \tilde{R}_{h}^{*}\left(s^{11}\right)$ & $E \tilde{R}_{l}\left(s^{12}\right), E \tilde{R}_{h}^{*}\left(s^{12}\right)$ \\
\hline $\begin{array}{l}\text { : } \\
\text { : }\end{array}$ & $q_{l} \& N X$ & $E \tilde{R}_{l}\left(s^{21}\right), E \tilde{R}_{h}^{*}\left(s^{21}\right)$ & $\frac{\bar{\theta} \lambda m q_{l}}{4}, \frac{\bar{\theta} q_{h}}{4}$ \\
\hline
\end{tabular}

Table A.2: Quality Strategy Profiles

- $s^{11}$ : under this strategy profile, the domestic firm continues to select the low-quality product and exports it to the foreign country; meanwhile the foreign firm chooses the high-quality product and exports it to the home country.

- $s^{12}$ : under this strategy profile, the foreign firm selects the high-quality product but chooses to strategically exit the domestic market; meanwhile the home firm continues to choose the low quality and exports it to the foreign market. The home firm is a monopolist at home.

- $s^{21}$ : under this strategy profile, the domestic firm continues to pick the low-quality product but chooses to strategically exit the foreign market; meanwhile the foreign firm continues to choose 
high quality and exports it to the foreign market. The foreign firm is a monopolist in its own market.

- $s^{22}$ : under this strategy profile, both firms pick their own quality but choose to strategically exit the export market. By doing so, both become monopolists in their respective local markets.

From the trade equilibrium, it is straightforward to determine the corresponding expected revenues: $E \tilde{R}_{l}\left(s^{11}\right)=\left[\frac{\lambda \bar{\theta}(m+1)^{2}}{m+\lambda / U}\right] \frac{\mu(\mu-1) q_{l}}{(4 \mu-1)^{2}} E \tilde{R}_{h}^{*}\left(s^{11}\right)=\left[\frac{4 \lambda \bar{\theta}(m+1)^{2}}{\lambda+m / U^{*}}\right] \frac{\mu(\mu-1) q_{h}}{(4 \mu-1)^{2}}$ To obtain revenues under strategy $s^{21}$ start by writing down profit functions:

$$
\begin{aligned}
& E \tilde{\pi}=p_{l} D_{l}-\frac{c}{2} q_{l}^{2} \\
& E \tilde{\pi}^{*}=U^{*} p_{h} D_{h}+p_{h}^{*} D_{h}^{*}-\frac{c^{*}}{2} q_{h}^{2}
\end{aligned}
$$

or

$$
\begin{aligned}
& E \tilde{\pi}=p_{l} m\left\{\frac{p_{h}-p_{l}}{\lambda \bar{\theta}\left(q_{h}-q_{l}\right)}-\frac{p_{l}}{\lambda \bar{\theta} q_{l}}\right\}-\frac{c}{2} q_{l}^{2} \\
& E \tilde{\pi}^{*}=U^{*} p_{h} m\left\{1-\frac{p_{h}-p_{l}}{\lambda \bar{\theta}\left(q_{h}-q_{l}\right)}\right\}+p_{h}^{*}\left\{1-\frac{p_{h}^{*}}{\bar{\theta} q_{h}}\right\}-\frac{c^{*}}{2} q_{h}^{2}
\end{aligned}
$$

In this case, the strict imposition of anti-dumping constraints (7) and (8) is too restrictive because the foreign firm has a monopoly in the production of high quality in its own market. Instead we determine the parameter space such that these above two conditions are verified. Reproducing the steps of Proposition 2, we obtain the following key solutions for prices: $p_{l}=\frac{\lambda \bar{\theta} q_{l}(\mu-1)}{(4 \mu-1)} ; p_{h}=\frac{2 \lambda \bar{\theta} q_{h}(\mu-1)}{(4 \mu-1)}$ Given these, domestic and foreign demands are computed and revenues derived:

$$
\begin{aligned}
& E \tilde{R}_{l}\left(s^{21}\right)=\frac{\lambda \bar{\theta} m q_{l}(\mu-1) \mu}{(4 \mu-1)^{2}} \\
& E \tilde{R}_{h}^{*}\left(s^{21}\right)=\frac{U^{*} 4 m \lambda \bar{\theta} q_{h} \mu(\mu-1)}{(4 \mu-1)^{2}}+\frac{\bar{\theta} q_{h}}{4}
\end{aligned}
$$

Similarly for strategy $s^{12}$ :

$$
\begin{aligned}
& E \tilde{R}_{l}\left(s^{12}\right)=\frac{m \lambda \bar{\theta} q_{l}}{4}+\frac{U \bar{\theta} q_{h}(\mu-1)}{(4 \mu-1)^{2}} \\
& E \tilde{R}_{h}^{*}\left(s^{12}\right)=\frac{4 \bar{\theta} q_{l}(\mu-1) \mu^{2}}{(4 \mu-1)^{2}}
\end{aligned}
$$

There are three Nash equilibria in the export-quality game of Table A.2, strategy $s^{22}$ being dominated by the other strategies. To establish when $s^{11}$ is a Nash equilibrium in Proposition 2, it is sufficient to compare $E \tilde{R}_{l}\left(s^{11}\right)>E \tilde{R}_{l}\left(s^{21}\right)$ and $E \tilde{R}_{h}^{*}\left(s^{11}\right)>E \tilde{R}_{h}^{*}\left(s^{12}\right)$. Particularly, $E \tilde{R}_{l}\left(s^{11}\right)>$ $E \tilde{R}_{l}\left(s^{21}\right)$ if and only if the following condition is satisfied:

$$
U>\lambda \frac{m}{(2 m+1)}
$$

Likewise $E \tilde{R}_{h}^{*}\left(s^{11}\right)>E \tilde{R}_{h}^{*}\left(s^{12}\right)$ if and only if: 


$$
\frac{1}{U^{*}(m+2)}<\lambda \leq \frac{2 U(\mu-1)}{(4 \mu-1)}
$$

This is a Nash equilibrium where all firms export while satisfying the anti-dumping constraint of the WTO.

\section{Exit Conditions}

To illustrate how exit conditions matter in the model, we focus on the other two strategies, namely $s^{21}$ and $s^{12}$. Let us first consider strategy profile $s^{21}=\left\{q_{l} \& N X, q_{h} \& X\right\}$ as it is the one leading to home firms export exit and eventually re-entry. To establish when $s^{21}$ is a Nash equilibrium, it is sufficient to compare $E \tilde{R}_{h}^{*}\left(s^{21}\right)$ with $\bar{\theta} q_{h} / 4$ and $E \tilde{R}_{l}\left(s^{21}\right)$ with $E \tilde{R}_{l}\left(s^{11}\right)$. Therefore $E \tilde{R}_{l}\left(s^{21}\right)>$ $E \tilde{R}_{l}\left(s^{11}\right)$ if and only if the following condition is satisfied:

$$
U<\frac{(\lambda m)}{2 m+1}
$$

which is inequality (17) in the text. This condition is always satisfied for $U \rightarrow 0$. More generally, an equivalent expression can be derived:

$$
m(2 U-\lambda)+U<0
$$

and thus $U<\lambda / 2$ is the necessary condition for (17) to be verified. Similarly, $E \tilde{R}_{h}^{*}\left(s^{21}\right)>\bar{\theta} q_{h} / 4$ if and only if:

$$
\frac{U^{*} 4 m \lambda \bar{\theta}(\mu-1) \mu q_{h}}{(4 \mu-1)^{2}}>0
$$

which is always satisfied as long as $U^{*}>0$. In addition the anti-dumping constraint for the foreign firm must be imposed. Namely, $U^{*} p_{h} \geq p_{h}^{*}$ implies:

$$
\frac{1}{\lambda} \frac{(4 \mu-1)}{4(\mu-1)} \leq U^{*}
$$

which is inequality (18). As both ratios on the LHS are larger than unity, $U^{*}$ must be larger than 1 as well. Existence conditions for the other strategy are computed in a similar way. Strategy profile $s^{12}=\left\{q_{l} \& X, q_{h} \& N X\right\}$ is the one leading to foreign firms export exit and re-entry. To establish when $s^{12}$ is a Nash equilibrium, it is sufficient to compare $E \tilde{R}_{l}\left(s^{12}\right)>\bar{\theta} \lambda m q_{l} / 4$ and $E \tilde{R}_{h}^{*}\left(s^{12}\right)>$ $E \tilde{R}_{h}^{*}\left(s^{11}\right)$. Therefore $E \tilde{R}_{l}\left(s^{12}\right)>\bar{\theta} \lambda m q_{l} / 4$ if and only if the following condition is satisfied:

$$
\frac{U \bar{\theta}(\mu-1) q_{h}}{(4 \mu-1)^{2}}>0
$$

which requires $U>0$. Likewise $E \tilde{R}_{h}^{*}\left(s^{12}\right)>E \tilde{R}_{h}^{*}\left(s^{11}\right)$ if and only if:

$$
\lambda \leq \frac{2 U(\mu-1)}{(4 \mu-1)}
$$


Moreover the anti-dumping constraint is satisfied if and only if:

$$
\lambda<\frac{1}{U^{*}(m+2)}
$$

(A.7) determines the parameter space such that anti-dumping conditions are verified. Intuitively, though the home firm applies its monopoly price, it satisfies the WTO constraints only when the home country is relatively poor, namely for small values of $\lambda$.

\section{B. Data Sources and Methods}

\section{Data sources}

This paper employs a data set that matches the firm surveys and trade transactions records collected by the Philippine Statistics Authority (PSA) from the period $1991-2012$. The firm survey data comprises eight Annual Survey of Establishments (1997, 1998, 2001, 2003, 2005, 2008, 2009 and 2010) and three Census of Philippine Business and Industry $\left(2000,2006\right.$ and 2012). ${ }^{21}$ All the large firms with 200 or more employees (in some years, 100 or more) were surveyed, while the rest are sampled. ${ }^{22}$

\section{Merging the data}

The PSA data consist of three main panels which in turn consist of many cross sections. Each panel has been merged separately before being merged with another panel. The first two main panels are from the customs data of the PSA. The customs data consist of separate cross sections for the export and import data. The magnitude of the import data is notably larger than the export data. The export cross section data from 1991-2012 is merged into one panel and the import data into a separate panel. There are a couple of minor adjustments made to the trade data. The trade codes are unique over time. Implying that no two firms can have the same trader code. This was indeed the case however in some cases firms that where indeed the same firm where given different trader codes over time. This could be due to spelling of the name and other minor discrepancies which lead to the assignment of a new trader code. Therefore the PSA cross checked the trader codes for consistency over time. Basically the PSA cross checked address, establishment control number, firm name and tax information number over time. This led to the correction 1614 firms with usually two however sometimes three trader codes. ${ }^{23}$ There are also a couple of examples of multiple firm branches operating under the same TC. The firm survey information of the respective branches is then combined to the unique trader code. This thorough cleaning of the data is only done for the list of establishments matched manufacturing data used in this paper.

The second correction involved matching the Pscc 7-digit classification (harmonized to the SITC rev3 untill 5 digits) to the Pscc 10-digit classification (Harmonized to the HS classification) which was used from 2006 onwards. The problem with correcting this change in classification is that in

\footnotetext{
${ }^{21}$ The 1997 survey is a combined survey covering both 1996 and 1997

${ }^{22}$ See Appendix for the data matching procedure and the PSA protocol for data use that assures the full confidentiality of the data.

${ }^{23}$ Firm names, for example, written with and without apostrophe that were given different trader codes. These and multiple of other examples confirm the uniqueness of the TC however endanger the consistency over time. Therefore its correction is of importance
} 
some cases a single 10-digit categories matches with multiple 7-digit categories. Clearly indicating that the change in classification is not only a switch to a more detailed classification. Actually the reverse is true in some cases. The Pscc 7-digit classification was tailored to the Philippine economy while the with the 10-digit classification was set up in order to harmonize trade statistics between ASEAN member countries. Therefore there are also 7-digits sectors that match to multiple 10-digit sectors a situation which would not occur if the 10-digit classification was only more detailed for every product category. In order to merge the data over time and insure consistency a 7-digit sector that the firm previously exported was taken as the corresponding classification. For example 10-digit product category A matches with 7-digit product category B, C and D however firm 1 only produced product B the year before then B is assigned to all product from 2006 onwards that are classified A. The number of single Pscc 10-digit categories with multiple 7-digit categories is very limited however when they where encountered the strategy was applied in order to ensure within firm consistency. ${ }^{24}$

The survey data was a lot more complex to merge. The manufacturing surveys changed over time comprising of more or less and different questions over time. The 2001 survey for example consisting of only 8 pages while the 2009 survey consist over 12 pages. Also within a year the PSA often had a short questionnaire for smaller firms and a more extensive survey for larger firms. All these differences made merging the manufacturing surveys a tedious process. Before matching the survey over time the questionnaires where compared and corresponding questions over time where given the same code. Therefore questions that appeared in multiple survey over time could be traced. Due to changing surveys over time multiple questions only appeared in part of the sample. Also even if a question did appear in a certain year the response to that specific question could be low. Therefore questions that appear in every survey limited. On top of this the manufacturing survey have a certainty stratum. Only firms with more than 100 or in some years 200 employees where in this certainty stratum. This implied that firms with fewer employees were subject to sampling. Therefore it are mostly large firms for which there is a panel in terms of firm surveys over time. Many small firms only appear in one survey. Due to the difference in questionnaires and sampling over time the panel dimension of matching the firms survey is very limited and mostly revolves around the very large firms which often appear in multiple survey.

\footnotetext{
${ }^{24}$ There are 486 10-digit products which match in most cases to two (68.3\%) up to a maximum of 35 7-digit product categories. To put this into perspective there are a total of 6,533 product categories that the Philippines export between 1991-2012.
} 


\section{List of Destinations}

The 181 destinations are: Afghanistan, Algeria, Angola, Antigua and Barbuda, Armenia, Australia, Austria, Azerbaijan, Bahamas, Bahrain, Bangladesh, Barbados, Belarus, Belgium, Belize, Benin, Bhutan, Bolivia, Bosnia and Herzegovina, Botswana, Brunei, Bulgaria, Burkina Faso, Burundi, Cambodia, Cameroon, Canada, Spain( including the destinations Canary Islands, Ceuta and Melilla), Cape Verde, China, Christmas island, Colombia, Comoros, Congo, Democratic republic of Congo, Costa Rica, Ivory Coast, Croatia, Cuba, Cyprus, Czech republic, Denmark, Dominican republic, Ecuador, Ethiopia, Fiji, Finland, France (including the destinations Mayotte and Reunion), Gabon, Gambia, Georgia, Ghana, Greece, Grenada, Guadeloupe, Guatemala, Guinea, Guyana, Haiti, Honduras, Hong Kong, Hungary, Iceland, India, Indonesia, Iran, Ireland, Israel, Italy, Jamaica, Japan (including the destinations Okinawa and other Nansei islands), Jordan, Kazakhstan, Kenya, South Korea, Kuwait, Kyrgyzstan, Laos, Latvia, Leeward and Windward islands, Lesotho, Libya, Lithuania, Luxembourg, Macau, Macedonia, Madagascar, Malawi, Malaysia (including Sabah and Sarawak), Maldives, Mali, Malta, Martinique, Mauritania, Mexico, Monaco, Mongolia, Morocco, Mozambique, Namibia, Nepal, Netherlands, New Zealand, Nicaragua, Niger, Nigeria, Norway, Oman, Pacific trust territory, Pakistan, Palau, Panama, Papua New Guinea, Paraguay, Peru, Poland, Portugal (including the destinations Azores and Madeira), Qatar, Romania, Russia, Rwanda, Saudi Arabia, Senegal, Seychelles, Singapore, Slovakia, Slovenia, Solomon Islands, South Africa, Sri Lanka, St. Lucia, St. Vincent and Grenadines, Sudan, Suriname, Swaziland, Sweden, Switzerland, Syria, Taiwan, Tajikistan, Tanzania, Thailand, Tonga, Trinidad and Tobago, Tunisia, Turkey, Uganda, UK, Ukraine, USA (including the destinations Guam, Midway Islands, U.S minor outlying islands, Northern Mariana islands, Hawaii and

Alaska), Uruguay, Vanuatu, Vietnam, Virgin Islands (British), Virgin Islands (U.S.), Yemen, Zambia and Zimbabwe. 


\section{Variable definitions}

Table D.1: Data Sources and Methods

\begin{tabular}{|c|c|c|c|}
\hline Variable Name & Description & Formula and notes & Sources \\
\hline $\operatorname{rlpop}_{d, t}$ & $\begin{array}{l}\text { Philippine }(h) \text { population } \\
\text { as a ratio of population of } \\
\text { destination } d\end{array}$ & $\frac{P O P_{h, t}}{P O P_{d, t}}$ & $\begin{array}{l}\text { World Bank WDI, WPT } \\
\text { (World Penn Table) } 7.1 \text {, } \\
\text { Statistics Bureau of } \\
\text { Japan, INSEE, } \\
\text { EUROSTAT and U.S } \\
\text { Census Bureau. }\end{array}$ \\
\hline$r l i p c_{d, t}$ & $\begin{array}{l}\text { Philippine income per } \\
\text { capita as a ratio of income } \\
\text { per capita of destination } \\
d\end{array}$ & $\frac{G D P p c_{h, t}}{G D P p c_{d, t}}$ & $\begin{array}{l}\text { World Bank WDI, WPT } \\
7.1\end{array}$ \\
\hline $\operatorname{reer}_{d, t+1}$ & $\begin{array}{l}\text { The percentage change in } \\
\text { the real bilateral exchange } \\
\text { rate expressed as real pe- } \\
\text { sos per unit of real desti- } \\
\text { nation currency from } t \text { to } \\
t+1 \text {. }\end{array}$ & $\begin{array}{c}\text { reer }_{d, t+1}= \\
\left(\frac{R X_{t+1}-R X_{t}}{R X_{t}}\right) \\
R X_{t}=\frac{\left(\frac{X_{\text {rate }}, t}{C P I_{h, t}}\right)}{\left(\frac{X \text { rate }_{d, t}}{C P I_{d, t}}\right)}\end{array}$ & $\begin{array}{l}\text { World Bank WDI, WPT } \\
7.1\end{array}$ \\
\hline iceberg $_{f, p, d . t}$ & $\begin{array}{l}\text { US\$ unitary transport } \\
\text { cost as a proportion of } \\
\text { received US } \$ \text { export price } \\
\text { by firm } f \text { for product } p \text { to } \\
\text { destination } d\end{array}$ & $\begin{array}{c}\left(\frac{T k_{f p d t}}{P k_{f p d t}+T k_{f p d t}}\right) \\
T k_{f p d t}-\text { Transport cost per kilo } \\
P k_{f p d t}-\text { FOB price per kilo }\end{array}$ & $\begin{array}{l}\text { World Bank WDI, WPT } \\
7.1\end{array}$ \\
\hline $\operatorname{tarif} f_{d, t}^{*}$ & $\begin{array}{l}\text { Simple average of applied } \\
\text { tariffs in destination } d\end{array}$ & & World Bank WDI \\
\hline$u n c(\tilde{e})_{d, t+1}$ & $\begin{array}{l}\text { Rolling coefficient of vari- } \\
\text { ation of the nominal pe- } \\
\text { sos per unit of destination } \\
\text { currency (rolling window } \\
\text { of } 5 \text { years } t-3 \text { till } t+1 \text { ) }\end{array}$ & $\begin{array}{c}u n c(\tilde{e})_{d, t+1}=\frac{\sigma_{t+1}}{\mu_{t+1}} \\
\sigma_{t+1}=\frac{1}{4} \sum_{i=t-3}^{t+1}\left(y_{i}-\mu_{t+1}\right)^{2} \\
\mu_{t+1}=\frac{1}{5} \sum_{i=t-3}^{t+1} y_{i}\end{array}$ & WPT 7.1 \\
\hline$u n c(\tilde{r})_{f, p, d, t}$ & $\begin{array}{l}\text { The medium percentage } \\
\text { change in transport costs } \\
\text { of all products that are ex- } \\
\text { ported by firms in both } \\
\text { periods } t-1 \text { and } t \text { to des- } \\
\text { tination } d \text {. }\end{array}$ & $\begin{array}{c}u n c(\tilde{r})_{f, p, d, t}= \\
\operatorname{Med}\left(\Delta T k_{11 d, t}, \Delta T k_{1 p d, t}, \ldots\right. \\
\left.\ldots, \Delta T k_{f p d, t}\right) \\
\Delta T k_{f p d, t}=\frac{T k_{f p d, t}-T k_{f p d, t-1}}{T k_{f p d, t}}\end{array}$ & PSA Customs Data \\
\hline Networkeffects $s_{p, d, t}$ & $\begin{array}{l}\text { The log of the number } \\
\text { of Philippine exporters ex- } \\
\text { porting a certain product } \\
\text { (7-digit Pscc) to a destina- } \\
\text { tion. }\end{array}$ & $\begin{array}{c}\text { Networkeffects } s_{p, d, t}= \\
\# E x_{p, d, t} \\
\# E x_{p, d, t}-\text { Number of exporters }\end{array}$ & PSA Customs Data \\
\hline
\end{tabular}


Table D.1 continued

\begin{tabular}{|c|c|c|c|}
\hline Variable Name & Description & Formula and notes & Sources \\
\hline \multirow[t]{2}{*}{$u n c\left(\tilde{\tau}^{*}\right)_{d, t}$} & \multirow{2}{*}{$\begin{array}{l}\text { Index of rule of law coeffi- } \\
\text { cient (normalized) of des- } \\
\text { tination relative to that of } \\
\text { the Philippines. }\end{array}$} & $\begin{array}{c}u n c\left(\tilde{\tau}^{*}\right)_{d, t}= \\
\frac{N R o L_{h, t}-N R o L_{d, t}}{N R o L_{h, t}}\end{array}$ & $\begin{array}{l}\text { Worldwide Governance } \\
\text { Indicators }\end{array}$ \\
\hline & & $N R o L_{d, t}=\frac{\left(R o L_{d, t}-\min \left(R o L_{t}\right)\right)}{\left(\max \left(\operatorname{RoL} L_{t}\right)-\min \left(\operatorname{RoL} L_{t}\right)\right)}$ & \\
\hline \multirow[t]{3}{*}{$R \& D_{i, t}$} & \multirow{3}{*}{$\begin{array}{l}\text { The percentage of firms } \\
\text { within a 5-digit PSIC } \\
\text { section that respond in } \\
\text { the manufacturing survey } \\
\text { that it invests in R\&D. } \\
\text { Therefore } 1 \text { indicates that } \\
\text { all the firms with a } 5 \text {-digit } \\
\text { PSIC section }(i) \text { that re- } \\
\text { sponded to the survey in- } \\
\text { dicated that they invested } \\
\text { in R\&D. }\end{array}$} & $R \& D_{i, t}=\frac{n r d_{i t}}{N_{i t}}$ & PSA Survey data \\
\hline & & $\begin{array}{c}n r d_{s t}=\text { Number of firms } \\
\text { in } i \text { investing in R\&D at } \\
\text { time } t\end{array}$ & \\
\hline & & $\begin{array}{l}N_{s t}=\text { Total number of } \\
\text { firms in } i \text { at time } t\end{array}$ & \\
\hline Dist $_{d}$ & $\begin{array}{l}\text { The natural logarithm of } \\
\text { the great circle distance } \\
\text { between the capital city of } \\
\text { the Philippines and that } \\
\text { of the respective destina- } \\
\text { tion. If the destination } \\
\text { had no capital city then } \\
\text { the largest city is taken. }\end{array}$ & $\ln \left(\right.$ Dist $\left._{d}\right)$ & $\begin{array}{l}\text { CEPII, Geodist database, } \\
\text { variable: distcap } \\
\text { Supplemented with own } \\
\text { caluclations using } \\
\text { http://www.movable- } \\
\text { type.co.uk/ great circle } \\
\text { distance latitude } \\
\text { longitude scrips }\end{array}$ \\
\hline Emp200 ft & $\begin{array}{l}\text { Dummy variable takes } \\
\text { value } 1 \text { when a firm has } \\
200 \text { or more employees. } \\
\text { Data is obtained from } \\
\text { the PSA manufacturing } \\
\text { survey and interpolated } \\
\text { for missing observations. } \\
\text { The certainty stratum of } \\
\text { the national survey is also } \\
\text { used. If a firm was not } \\
\text { surveyed then that firm } \\
\text { had at least fewer than } \\
200 \text { employees }\end{array}$ & & PSA Survey data \\
\hline rlxprice $_{m d, f p d t}$ & $\begin{array}{l}\text { US } \$ \text { price of firm } f \text { ex- } \\
\text { porting product } p \text { to des- } \\
\text { tination } d \text { at time } t \text { rel- } \\
\text { ative to the median US\$ } \\
\text { price of the same prod- } \\
\text { uct imported into the } \\
\text { Philippines. }{ }^{(i)(i i)}\end{array}$ & $\ln \left(\frac{x_{p r i c e_{f p d t}}}{\operatorname{Med}\left(\text { mprice }_{p t}\right)}\right)$ & PSA customs data \\
\hline
\end{tabular}

Continued on next page 
Table D.1 continued

\begin{tabular}{|c|c|}
\hline $\begin{array}{l}\text { Variable Name } \\
\text { rlxprice }_{m, f p d t}\end{array}$ & $\begin{array}{l}\text { Description } \\
\text { US } \$ \text { price of firm } f \text { ex- } \\
\text { porting product } p \text { to des- } \\
\text { tination } d \text { at time } t \text { rel- } \\
\text { ative to the mean US\$ } \\
\text { price of the same prod- } \\
\text { uct imported into the } \\
\text { Philippines. }\end{array}$ \\
\hline & Industry Dummies \\
\hline $\operatorname{Ind}(1)$ & Dummy variables takes the value 1 product is in PSCC section $0 ; 0$ otherwise. \\
\hline $\operatorname{Ind}(2)$ & Dummy variables takes the value 1 product is in PSCC section $1 ; 0$ otherwise. \\
\hline $\operatorname{Ind}(3)$ & Dummy variables takes the value 1 product is in PSCC section $2 ; 0$ otherwise. \\
\hline $\operatorname{Ind}(4)$ & Dummy variables takes the value 1 product is in PSCC section $3 ; 0$ otherwise. \\
\hline $\operatorname{Ind}(5)$ & Dummy variables takes the value 1 product is in PSCC section $4 ; 0$ otherwise. \\
\hline $\operatorname{Ind}(6)$ & Dummy variables takes the value 1 product is in PSCC section $5 ; 0$ otherwise. \\
\hline $\operatorname{Ind}(7)$ & $\begin{array}{l}\text { Dummy variables takes the value } 1 \text { product is in PSCC section } 68+667 ; 0 \\
\text { otherwise. }\end{array}$ \\
\hline $\operatorname{Ind}(8)$ & Dummy variables takes the value 1 product is in PSCC groups 971 ; 0 otherwise. \\
\hline $\operatorname{Ind}(9)$ & $\begin{array}{l}\text { Dummy variables takes the value } 1 \text { product is in PSCC divisions } 61+63+64 \\
+65+66 ; 0 \text { otherwise. }\end{array}$ \\
\hline $\operatorname{Ind}(10)$ & $\begin{array}{l}\text { Dummy variables takes the value } 1 \text { product is in PSCC divisions } 67+69 ; 0 \\
\text { otherwise. }\end{array}$ \\
\hline $\operatorname{Ind}(11)$ & Dummy variables takes the value 1 product is in PSCC division $62 ; 0$ otherwise. \\
\hline $\operatorname{Ind}(12)$ & $\begin{array}{l}\text { Dummy variables takes the value } 1 \text { product is in PSCC groups } 785+786+ \\
791+703 ; 0 \text { otherwise. }\end{array}$ \\
\hline $\operatorname{Ind}(13)$ & $\begin{array}{l}\text { Dummy variables takes the value } 1 \text { product is in PSCC groups } 71+72+73 \\
+74+77-776+781+782+783+784 ; 0 \text { otherwise. }\end{array}$ \\
\hline $\operatorname{Ind}(14)$ & $\begin{array}{l}\text { Dummy variables takes the value } 1 \text { product is in PSCC groups } 75+776+76 \\
+792 ; 0 \text { otherwise. }\end{array}$ \\
\hline $\operatorname{Ind}(15)$ & $\begin{array}{l}\text { Dummy variables takes the value } 1 \text { product is in PSCC groups } 82+83+85 \\
+894 ; 0 \text { otherwise. }\end{array}$ \\
\hline $\operatorname{Ind}(16)$ & $\begin{array}{l}\text { Dummy variables takes the value } 1 \text { product is in PSCC groups } 895+899+ \\
892+897+898+896 ; 0 \text { otherwise. }\end{array}$ \\
\hline $\operatorname{Ind}(17)$ & Dummy variables takes the value 1 product is in PSCC groups 893 ; 0 otherwise. \\
\hline $\operatorname{Ind}(18)$ & $\begin{array}{l}\text { Dummy variables takes the value } 1 \text { product is in PSCC groups } 87+88+891 \\
\text {; } 0 \text { otherwise. }\end{array}$ \\
\hline $\operatorname{Ind}(19)$ & Dummy variables takes the value 1 product is in PSCC groups 971 ; 0 otherwise. \\
\hline $\operatorname{consign}_{f p d t}$ & $\begin{array}{l}\text { Dummy variables takes the value } 1 \text { product is in PSCC groups } 93101+93102 \\
; 0 \text { otherwise. }\end{array}$ \\
\hline \multicolumn{2}{|c|}{ 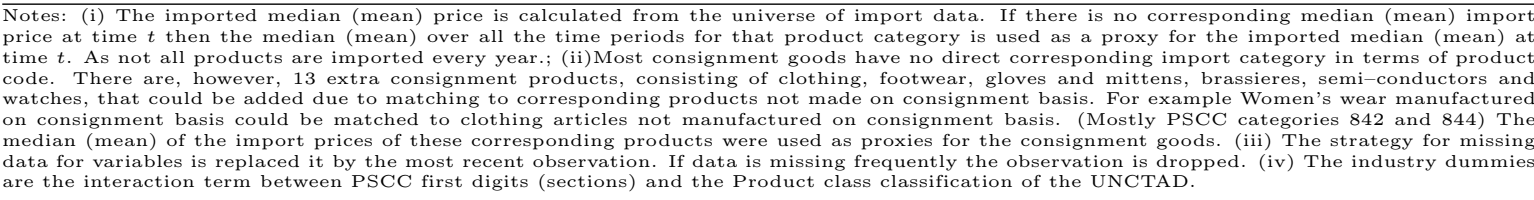 } \\
\hline
\end{tabular}


Figure E.1: Distribution of bilateral relative quality

a. Hong Kong

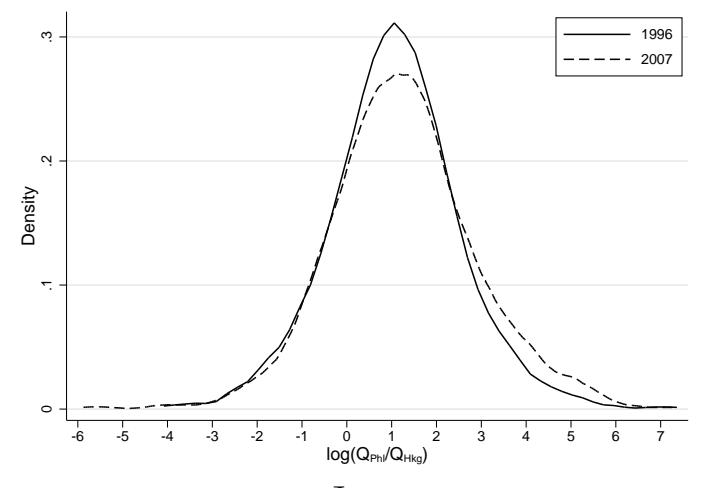

c. Japan

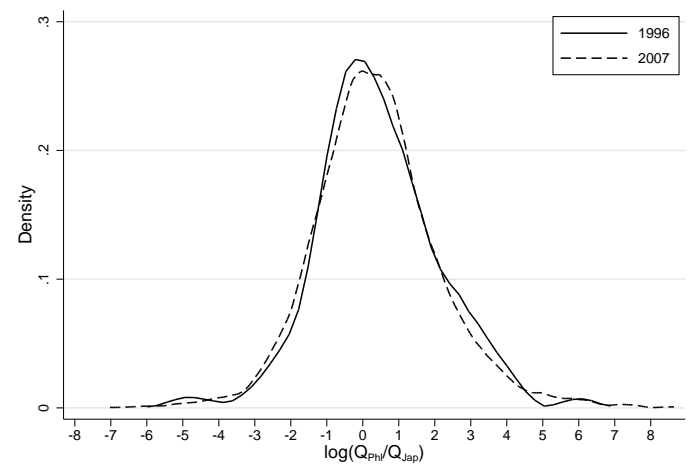

e. China

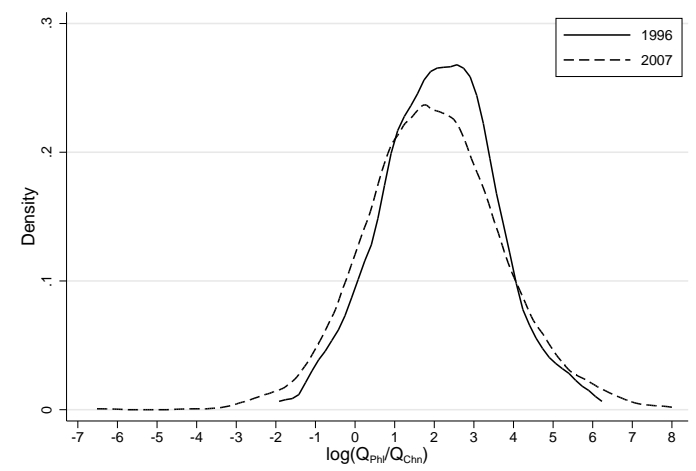

b. Singapore

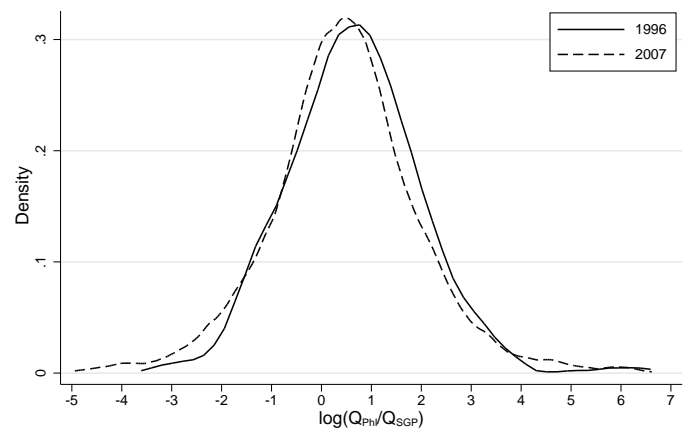

d. Taiwan

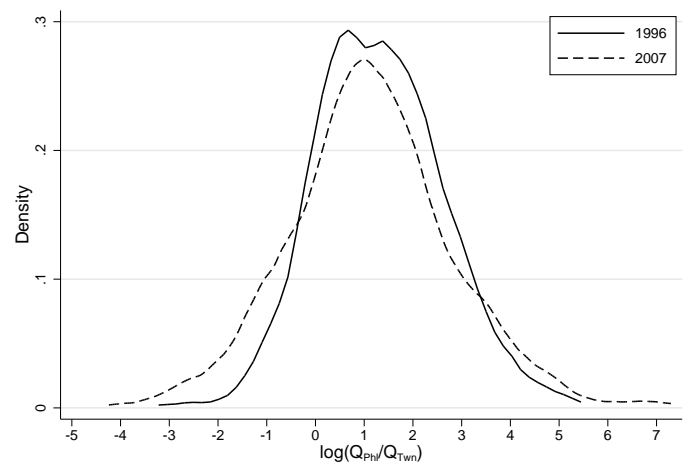

f. Thailand

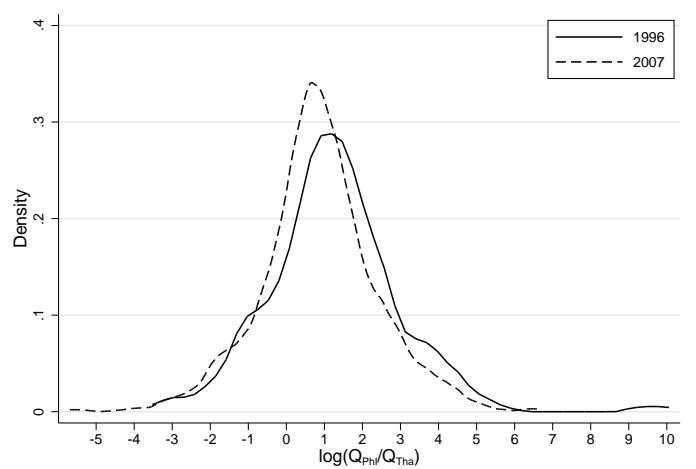

Notes: All observations for which there is a match between the median import and export product are included in the sample. The imported median price is calculated from the universe of bilateral import data. If there is no corresponding real median import price at time $t$ for product $i$ then the median over all the time periods for that product is used as a proxy for the imported median at time $t$. As
not all products are imported every year. The Kernel used for the figures is Epanechnikov. 